\title{
CONTRIBUCIÓN AL EPISTOLARIO DE FEIJOO: UNA CARTA INÉDITA AL GENERAL LASANTA $(1755)^{*}$
}

\author{
Guillermo Fernández OrTiz \\ Universidad de Oviedo \\ ORCID iD: http://orcid.org/0000-0002-4572-8236 \\ RODRIGO OLAY VALDÉS \\ Universidad de Oviedo-Instituto Feijoo de Estudios del Siglo XVIII \\ ORCID iD: http://orcid.org/0000-0002-9611-092X
}

\begin{abstract}
* Esta investigación se enmarca en los proyectos de investigación I+D Notariado y construcción social de la realidad. Hacia una codificación del documento notarial (PGC2018-093495-B-I00), financiado por FEDER / Ministerio de Ciencia e Innovación / Agencia Estatal de Investigación, y Biografias y polémicas: hacia la institucionalización de la literatura y el autor (RTI2018-095664-BC21) del Ministerio de Ciencia, Innovación y Universidades (Programa estatal de investigación. Programa estatal de I+D+I orientado a los retos de la sociedad actual). Es de obligado cumplimiento agradecer a los padres Lorenzo Maté (O.S.B., monasterio de Santo Domingo de Silos) y José Luis Vélez (O.S.B., monasterio de San Julián Samos) y a sor M. ${ }^{\mathrm{a}}$ Covadonga Querol de Bascarán (O.S.B., monasterio de San Pelayo de Oviedo) las facilidades para la consulta de los archivos de sus respectivas comunidades. Los agradecimientos deben extenderse a Paulino Pandiella Gutiérrez y Eduardo San José Vázquez por la colaboración prestada para el desarrollo de esta investigación.
\end{abstract}

Copyright: (C) 2021 CSIC. La edición electrónica de esta revista se distribuye bajo los términos de una licencia de uso y distribución Creative Commons Reconocimiento 4.0 Internacional (CC BY 4.0).

Cómo citar/Citation: Guillermo FernáNDEZ ORTIZ, Rodrigo OlAY VALDÉS, "Contribución al epistolario de Feijoo: una carta inédita al General Lasanta (1755)", Cuadernos de Estudios Gallegos, 68, núm. 134 (2021), págs. 307-336, https://doi.org/10.3989/ceg.2021.134.10 


\title{
CONTRIBUCIÓN AL EPISTOLARIO DE FEIJOO: UNA CARTA INÉDITA AL GENERAL LASANTA (1755)
}

\begin{abstract}
RESUMEN
En el presente estudio se ofrece en edición crítica la carta inédita que Benito Jerónimo Feijoo escribió a fray Diego Vítores de Lasanta, General de la Congregación de San Benito de Valladolid, en 1755, a propósito de la división regional de oficios y responsabilidades que la Congregación había asumido en 1749, una vez obtenida la Bula de Benedicto XIV, que permitía la reforma de su secular régimen de gobierno. Los objetivos que nos proponemos son, en primer lugar, contribuir al conocimiento del epistolario feijoniano, con el estudio de una carta hasta el momento inédita; en segunda instancia, procederemos a valorar la participación del monje gallego en los asuntos de la Congregación, a través, en este caso, de su juicio en un asunto de inequívoca trascendencia: la asunción de nuevos criterios para la elección de sus cargos.

Palabras Clave: Benito Jerónimo Feijoo, Congregación benedictina de Valladolid, Epistolario, Cuatripartita.
\end{abstract}

\section{CONTRIBUCIÓN AO EPISTOLARIO DE FEIXOO: UNHA CARTA NON PUBLICADA AO XERAL LASANTA (1755)}

\section{RESUMO}

Este estudo ofrece unha edición crítica da carta inédita que Benito Xerónimo Feixoo escribiu a Fray Diego Vítores de Lasanta, xenal da Congregación de San Benito de Valladolid, en 1755 , relativa á división rexional de oficios e responsabilidades que a Congregación tiña asumido en 1749, unha vez obtida a bulla de Benito XIV, o que permitiu a reforma do seu réxime secular de goberno. Os obxectivos que nos propoñemos son, en primeiro lugar, contribuír ao coñecemento do epistolario feixoniano, co estudo dunha carta ata agora inédita; en segundo lugar, procederemos a avaliar a participación do relixioso galego nos asuntos da Congregación, mediante, neste caso, o seu xuízo en cuestión de transcendencia inequívoca: a asunción de novos criterios para a elección das súas posicións.

Palabras ClaVe: Benito Xerónimo Feixoo, Congregación benedictina de Valladolid, Epistolario, Cuadripartita.

\section{CONTRIBUTION TO THE STUDY OF FEIJOO'S EPISTOLARY: AN UNPUBLISHED LETTER TO GENERAL LASANTA (1755)}

\begin{abstract}
This study offers a critical edition of the unpublished letter that Benito Jerónimo Feijoo addressed to Fray Diego Vítores de Lasanta, General of the Congregation of San Benito de Valladolid, in 1755, regarding the regional division of offices and responsibilities that the Congregation had taken on in 1749 , after receiving the papal bull from Benedict XIV, allowing the reform of its secular regime of government. This paper has two main objectives: first of all, to contribute to the knowledge of the Feijonian epistolary; secondly, to study the participation of the Galician monk in the affairs of the Congregation, in this case, through his trial in a matter of unequivocal significance: the acceptance of new criteria for the election of officials within the order.

KEY WORDS: Benito Jerónimo Feijoo, Benedictine Congregation of Valladolid, Epistolary, Quadripartite.
\end{abstract}


Recibido/Received: 28/05/2020

Aceptado/Accepted: 18/10/2020

\section{El EPISTOLARIO PRIVAdo DE FeIJOO ${ }^{1}$}

Hace ya muchos años que los especialistas vienen interesándose por el epistolario de Benito Jerónimo Feijoo (1676-1764), materia que ha merecido apoximaciones recientes de la mayor relevancia; a la cabeza de todas ellas, la muy valiosa tesis doctoral de Noelia García Díaz, defendida en la Universidad de Oviedo en febrero de 2016 y por el momento inédita ${ }^{2}$.

En muy variados lugares de su voluminosa obra escrita hace Feijoo referencia a la vastedad de su epistolario, que no es exagerado suponer compuesto por miles de cartas. Por allegar una sola cita, bien pronto confiesa el benedictino, en 1734, que sufre «una especie de tedio en el ejercicio de escribir cartas, ocasionado en la continuada precisión en que me vi por largo espacio de tiempo de escribir muchas» ${ }^{3}$.

Sin embargo, pese a las importantes aportaciones de numerosos especialistas, el epistolario conocido de Feijoo no acaba de alcanzar las dimensiones que cabría suponerle ${ }^{4}$. Ciñéndonos a los últimos sesenta años, José Simón Díaz', Guadalupe de la Noval ${ }^{6}$, Antonio Mestre ${ }^{7}$, Francisco Aguilar Piñal ${ }^{8}$ o Maximino

\footnotetext{
${ }^{1}$ Abreviaturas empleadas: AHN (Archivo Histórico Nacional); AMSDS (Archivo del Monasterio de Santo Domingo de Silos); AMSJS (Archivo del Monasterio de San Julián de Samos); AMSPO (Archivo del Monasterio de San Pelayo de Oviedo); BA (Biblioteca de Asturias); BNE (Biblioteca Nacional de España).

${ }^{2}$ Noelia García Díaz, El epistolario de Benito Jerónimo Feijoo (en los inicios del ensayo moderno), Tesis doctoral, Oviedo, Universidad de Oviedo, 2016.

3 Antonio Mestre, "Correspondencia Feijoo-Mayans en El Colegio del Patriarca", Anales del Seminario de Valencia, 4 (1964), pág. 181.

${ }^{4}$ Aun asumiendo las dificultades y limitaciones para la escritura de cartas por parte de los monjes que imponían las Constituciones de la Congregación de Nuestro Glorioso Padre San Benito de España e Inglaterra, Madrid, Imprenta Real, 1671, cap. 39, núms. 14-15.

5 José Simón Díaz, "Una carta inédita del P. Feijoo", Cuadernos de Estudios Gallegos, 9 (1948), págs. $150-151$.

"Guadalupe de la Noval, "Cuatro cartas autógrafas del Padre Feijoo al Padre Sarmiento", Yermo, Cuadernos de Historia y de Espiritualidad Monástica, 2 (1964), págs. 262-265.

${ }^{7}$ Mestre, “Correspondencia Feijoo-Mayans...", págs. 149-186.

${ }^{8}$ Francisco Aguilar PiÑal, "La primera carta cruzada entre Campomanes y Feijoo", Boletín del Centro de Estudios del Siglo XVIII, 1 (1973), págs. 14-20.
} 
Arias $^{9}$ dieron a conocer cartas del monje; en esta serie, descuella la Bibliografía feijoniana publicada en 1981 por José Miguel Caso González y Silverio Cerra Suárez, en la que se censan hasta 67 cartas del benedictino, muchas inéditas por aquellos días ${ }^{10}$. Desde entonces, José Martínez de la Escalera ${ }^{11}$, María Luisa Álvarez de Toledo ${ }^{12}$, Cristina González Caizán ${ }^{13}$, José Luis Pérez de Castro ${ }^{14}$, Eduardo San José Vázquez ${ }^{15}$ o María Rosa Saurin de la Iglesia ${ }^{16}$ han contribuido al estudio de otras misivas del benedictino. En fin, la obra capital en la materia es hoy por hoy, sin lugar a dudas, la ya citada tesis doctoral de García Díaz ${ }^{17}$, que, en curso de publicación, constituye un corpus de 159 cartas enviadas y recibidas por el benedictino desde 1724 hasta 1763. De ellas 20 son aún inéditas.

Más allá de estas cifras, es imprescindible tener presente, en reciente descubrimiento de Inmaculada Urzainqui, principal estudiosa de Feijoo y directora de la edición de sus Obras completas ${ }^{18}$, que muchas de las misivas que componen los cinco tomos de las Cartas eruditas y curiosas (1742-1760) de Feijoo son en realidad cartas privadas reaprovechadas por él para su publicación, una vez eliminados sus aspectos más circunstanciales ${ }^{19}$, lo que pone de manifiesto una vez más el valor de su epistolario privado.

\footnotetext{
9 Maximino Arias, "Catorce cartas de Feijoo a Sarmiento", Boletín del Centro de Estudios del Siglo XVIII, 4-5 (1977), págs. 5-69.

10 José Miguel Caso González y Silverio Cerra Suárez, Benito Jerónimo Feijoo. Obras completas, $t$. I, Bibliografia, Oviedo, Centro de Estudios del Siglo XVIII, 1981.

11 José Martínez de la Escalera, "Isla ante Feijoo", en Homenaje a Pedro Sainz Rodríguez, t. III, Madrid, Fundación Universitaria Española, 1986, págs. 471-486.

${ }^{12}$ Luisa Álvarez de Toledo, "En torno a una carta inédita de Feijoo", Revista de Literatura, XLIX, 98 (1987), págs. 564-573.

13 Cristina GonzÁlez CAIZÁn, "Correspondencia erudita entre don Agustín Pablo de Ordeñana y el Padre Feijoo”, BROCAR, 23 (1999), págs. 59-86.

14 José Luis Pérez de CASTRo, "Dos cartas inéditas del padre Feijoo a don Pedro Peón (julio de 1739)", en Inmaculada Urzainqui y Rodrigo Olay Valdés (eds.), Con la razón y la experiencia. Feijoo 250 años después, Oviedo, Instituto Feijoo de Estudios del Siglo XVIII-Universidad de Oviedo; Ayuntamiento de Oviedo; Trea, 2016, págs. 519- 532.

15 Eduardo SAn JosÉ VÁzQuez, "Corresponsales peruanos de Feijoo”, en Inmaculada Urzainqui y Rodrigo Olay Valdés (eds.), Con la razón y la experiencia. Feijoo 250 años después, Oviedo, Instituto Feijoo de Estudios del Siglo XVIII-Universidad de Oviedo; Ayuntamiento de Oviedo; Trea, 2016, págs. 533-548.

${ }^{16}$ María Rosa SAurin DE LA Iglesia, "Un corresponsal del P. Feijoo: Joaquín Saurin Robles”, Cuadernos de Estudios del Siglo XVIII, 28 (2018), págs. 311-342.

17 Por el momento hemos de contentarnos con la publicación de algunos estudios parciales, Noelia GARCÍA DíAz, "Corresponsales americanos de Benito Jerónimo Feijoo en las redes de Martín Sarmiento", en Gloria Ángeles Franco Rubio, Natalia González Heras y Elena de Lorenzo Álvarez (coords.), España y el continente americano en el siglo XVIII, Gijón, Trea, 2017, págs. 413-430.

18 De los valiosos trabajos de la profesora Urzainqui, podemos destacar, entre sus más recientes publicaciones, su estudio Inmaculada UrZAINQUI, "La república amistosa de las Cartas eruditas de Feijoo", Dieciocho. Hispanic Enlightenment, Anejo 5 (2019), págs. 373-398, de tan singulares aportaciones al conocimiento de los corresponsales de Feijoo.

19 Imaculada UrZAInQUI, "Estudio introductorio", en Benito Jerónimo Feijoo, Obras completas, t. II, Cartas eruditas y curiosas, I, ed. de Inmaculada Urzainqui y Eduardo San José Vázquez, Oviedo, Instituto Feijoo de Estudios del Siglo XVIII; Ayuntamiento de Oviedo; KRK, 2014, págs. 68-78.
} 
En definitiva, el objetivo de estas páginas es precisamente contribuir al conocimiento del epistolario feijoniano con la edición de la carta que en 1755 el benedictino escribió al entonces General de San Benito de Valladolid, fray Diego Vítores de Lasanta. Un texto inédito hasta la fecha, pero cuya existencia no era ignorada por la bibliografía monástica ${ }^{20}-$ sí por los especialistas feijonianos- $\mathrm{y}$ que permite ver al monje participando en los asuntos de su Congregación, acaso la faceta menos tratada del ilustre benedictino.

\section{Feijoo en los asuntos de la Congregación}

En sucesivas ocasiones se ha señalado que el proyecto intelectual que emprendió el padre Feijoo no fue estrictamente individual, sino que aunaba a la iniciativa personal el apoyo sin fisuras de la Congregación de San Benito de Valladolid en su conjunto ${ }^{21}$. Poco a poco conocemos mejor el lugar exacto que ocupó el sabio de Casdemiro entre sus correligionarios. Así, sabemos de su profunda amistad con el padre Sarmiento ${ }^{22}$ y del apoyo que le brindaron públicamente sus compañeros de hábito cuando más arreciaron las críticas ${ }^{23}$. Su aprecio por aquellos que ostentaron los cargos de responsabilidad en el seno de la Congregación parece incuestionable ${ }^{24}$, como también lo es su respeto y veneración hacia los que fueron sus maestros. Lejos de las altas esferas, sus escritos, tanto los destinados al gran público como los de carácter privado, están plagados de nombres o referencias a religiosos y religiosas que abrazaron como él la regla benedictina: los tomos del Teatro crítico y de las Cartas eruditas ${ }^{25}$, su correspon-

\footnotetext{
${ }^{20}$ Había noticia de la existencia de esta carta en Ernesto Zaragoza PAScuAL, Los Generales de la Congregación de San Benito de Valladolid (1701-1801), t. V, Silos, Abadía de Silos, 1984, págs. 150 (n. 17) y 158 (n. 13); también en Ernesto Zaragoza PAScual, "Reivindicación del generalato de la Congregación de Valladolid para los monjes asturianos (1760)", Boletín del Instituto de Estudios Asturianos, 132 (1989), pág. 765 (n. 18).

${ }^{21}$ Inmaculada URZAINQUI, "Feijoo y su autorrepresentación como escritor", en Elena de Lorenzo Álvarez (coord.), Ser autor en la España del siglo XVIII, Gijón, Trea, 2017, pág. 52.

${ }^{22} \mathrm{Al}$ respecto anotó algunas consideraciones Maximino ARIAS CuENLLÁs, Historia del monasterio de San Julián de Samos, Samos, Monasterio de Samos, 1992, págs. 303-306; más recientemente puede verse el texto fundamental de Joaquín Álvarez BARrientos, "Para la historia de una amistad: Feijoo (1676-1764) y Sarmiento (1695-1772)", en Inmaculada Urzainqui y Rodrigo Olay Valdés (eds.), Con la razón y la experiencia. Feijoo 250 años después, Oviedo, Instituto Feijoo de Estudios del Siglo XVIII-Universidad de Oviedo; Ayuntamiento de Oviedo; Trea, 2016, págs. 489-508.

23 José Miguel CASo GonZÁlez, "Los benedictinos asturianos y la Ilustración”, en Semana de Historia del monacato cántabro-astur-leonés, Oviedo, Monasterio de San Pelayo de Oviedo, 1982, págs. 635-640. ${ }^{24}$ Distintos Generales de la Congregación figuran como dedicatarios de varios de los tomos del Teatro. Ha destacado el particular Pedro Álvarez De Miranda, "Los paratextos de las obras de Feijoo", en Inmaculada Urzainqui y Rodrigo Olay Valdés (eds.), Con la razón y la experiencia. Feijoo 250 años después, Oviedo, Instituto Feijoo de Estudios del Siglo XVIII-Universidad de Oviedo; Ayuntamiento de Oviedo; Trea, 2016, págs. 334-335.

${ }^{25}$ Entre un centón de referencias, véanse las menciones a su condiscípulo "de grandes fuerzas", fray Juan de Vellisca (Benito Jerónimo FeIJoo, Obras completas, T. III: Cartas eruditas y curiosas, II, ed. de
} 


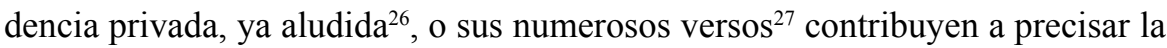
red de relaciones tejida por el benedictino. En fin, como tantos otros religiosos ${ }^{28}$, nunca dejó de favorecer el desarrollo de su casa de profesión ${ }^{29}$.

Sin embargo, sus tres abaciadgos en el monasterio San Vicente de Oviedo $(1721-1723,1727-1731,1737-1741)^{30}$ siguen siendo un absoluto misterio y casi nada sabemos de su intervención en los asuntos de la Congregación ${ }^{31}$, así como de las opiniones que pudieron generar sus juicios en distintas disputas suscitadas en el seno de la misma ${ }^{32}$. Además, este vacío historiográfico viene a coincidir con la imagen unitaria que los estudios sobre la Congregación de San Benito de Valladolid han insistido en mostrar, especialmente desde el punto de vista intelectual, campo en el que parece innegable el carácter corporativo de sus proyectos, siempre en relación con sus hermanos franceses de la Congregación de San Mauro ${ }^{33}$. Fuera de la esfera cultural, en relación a la vida interna, se

\footnotetext{
Inmaculada Urzainqui, Eduardo San José Vázquez y Rodrigo Olay Valdés, Oviedo, Instituto Feijoo de Estudios del Siglo XVIII, Ayuntamiento de Oviedo, KRK, 2018, págs. 197-199).

${ }^{26}$ Sobre los corresponsales benedictinos de Feijoo debe verse el trabajo fundamental ya citado de GARCÍA DíAz, El epistolario... Además, en las propias cartas las referencias a otros compañeros de hábito son constantes.

${ }^{27}$ Benito Jerónimo Feijoo, Obras completas. T. VII. Poesía, ed. de Rodrigo Olay Valdés, Oviedo, Instituto Feijoo de Estudios del Siglo XVIII-Universidad de Oviedo; Ayuntamiento de Oviedo, 2019, págs. 62-70 y 203-363.

28 Zaragoza Pascual, Los Generales..., t. V, passim.

29 Arias Cuenllás, Historia del monasterio..., págs. 274-275; y más recientemente ha aportado nuevas informaciones sobre el particular Javier GonZÁlez SANTOS, "Contribución del Padre Feijoo a la fábrica de la nueva iglesia del monasterio de San Julián de Samos (Lugo). Un capítulo documentado de la historia de la arquitectura y de la edición de libros en España”, Cuadernos de Estudios Gallegos, 130 (2017), págs. 313-356.

30 Ernesto Zaragoza Pascual, "Abadologio del Monasterio de San Vicente de Oviedo", Studium ovetense, 26 (1998), págs. 135-175.

31 [Pleito de fray Benito Jerónimo Feijoo, General de la Orden de San Benito y abad de San Vicente de Oviedo, junto a fray José Perales, abad de San Salvador de Celorio, contra la Administración de Rentas y Aduana]. AHN, Clero, Regular, Benedictinos, Celorio, leg. 4956; existe ejemplar fotocopiado en la Biblioteca Pública "Jovellanos" (Gijón), signatura B.A. FF 169-15. Participó con distintos encargos y comisiones (Maximino ARIAS, “Catorce cartas...”, págs. 42-44) e intervino en la solución de algunas eventualidades acontecidas en Capítulo General, como en mayo de 1737, a propósito de la "impotencia física de la vista del abad de Zamora" y su participación de la elección de General (AMSDS, Fondo de la Congregación de San Benito de Valladolid, Libro Actas III, fols. 76v. ${ }^{\circ}-77 \mathrm{r}^{\circ}{ }^{\circ}$ ). Este asunto de la legitimidad en los votos para la elección aparece consignado en las Constituciones..., 1671, fols. 25v. ${ }^{\circ}-26$ r. $^{\circ}$, así como el procedimiento que se ha de seguir, minuciosamente regulado.

32 Véanse por ejemplo, los términos que emplea a propósito de la elección de fray Miguel de Herze como General (Benito Jerónimo FejJoo, Suplemento del Teatro crítico, Madrid, Herederos de Francisco de el Hierro, 1740, s. f. [Dedicatoria]), tema sobre el que vuelve a escribir en la carta cuya edición ofrecemos. 33 Sin ánimo de exhaustividad, pueden citarse José Antonio FERNÁNDEZ FlóREZ, "La Congregación benedictina de Valladolid en el siglo XVIII", en Francisco Gimeno Blay (ed.), Erudición y discurso histórico: las instituciones europeas (s. XVIII-XIX), Valencia, Universitat de Valencia, 1993, págs. 101-128; Michel Dubuis "San Vicente de Salamanca, inicial de "movimiento erudito" en el tránsito del siglo XVII al siglo XVIII", en Pierre Civil y Françoise Crémoux (eds.), Nuevos caminos del hispanismo. Actas del XVI
} 
reconocen problemas coyunturales y se asumen inevitables enfrentamientos personales $^{34}$, pero nada, por el momento, que permita definir el ambiente de la Congregación en términos distintos a los empleados por Domínguez Ortiz para caracterizar a una vida monacal que discurría «dentro de un clima monótono, sereno y apacible, sin más incidentes que los causados por los preparativos de los capítulos y la renovación de cargos» ${ }^{35}$.

\section{FEIJOO Y LA DIVISIÓN CUATRIPARTITA DE LA RELIGIÓN}

Precisamente, con la carta que ofrecemos en edición crítica, Feijoo participó en uno de los altercados que alteró en el tercio central del siglo XVIII ese «clima monótono, sereno y apacible» que caracterizaba Domínguez Ortiz. El benedictino lo hacía por extenso, con fecha de 27 de agosto de 1755, a petición del abad general fray Diego Vítores de Lasanta, que desea disponer por escrito de sus reflexiones a propósito de la reciente división de la Congregación en cuatro partidos -Galicia, Tierra de Campos, La Rioja e Indiferentes-, aprobada por la Santa Sede en 24 de marzo 1749 y confirmada por el Capítulo General de la religión en mayo de $1753^{36}$. Con esta reforma se pretendía remediar la desigualdad apreciada en el acceso a los oficios y empleos de relevancia en el seno de la orden que tenían los naturales de las distintas naciones o partidos que componían la religión ${ }^{37}$.

El asunto, en cualquier caso, no era nuevo al mediar el siglo XVIII. La centuria anterior ya había conocido conatos similares o, al menos, reclamaciones de distinta entidad y limitado alcance, si bien nada invitaba a preludiar el énfasis que adquirió el movimiento regionalista en los años centrales del setecientos ${ }^{38}$. Estas iniciativas de corto alcance, inconexas entre sí y que aparecen intermitentemente a lo largo de todo este siglo ya habían traído consigo la división de la Congregación en tres partidos -Tierra de Campos, La Rioja y Galicia- ${ }^{39}$, así

\footnotetext{
Congreso de la Asociación Internacional de Hispanistas, Madrid-Frankfurt an Main, IberoamericanaVervuert, 2010, págs. 74-84; y, últimamente, Michel DubuIs, "Del concepto de un movimiento erudito, componente de la Pre-Ilustración”, Cuadernos de Estudios del Siglo XVIII, 30 (2020), págs. 165-190.

34 Zaragoza Pascual, Los Generales..., t. V, passim.

35 Antonio Domínguez OrTiz, La sociedad española en el siglo XVII, t. II, El estamento eclesiástico, Madrid, Consejo Superior de Investigaciones Científicas, 1970, pág. 87.

36 Zaragoza Pascual, Los Generales..., t. V, pág. 162.

37 Carta aquí editada, párrafo $\S 1$.

38 Zaragoza Pascual, Los Generales..., pág. 21; Baudilio Barreiro Mallón, "Los problemas del clero vistos desde las Juntas del Reino de Galicia, 1599-1750", Obradoiro de Historia Moderna, 14 (2005), pág. 21.

39 Ernesto Zaragoza Pascual, Los Generales de la Congregación de San Benito de Valladolid (16131701), t. IV, Silos, Abadía de Silos, 1982, pág. 261. Más detalle en Constituciones..., 1671, fols. 56v. ${ }^{\circ}$ 60v. ${ }^{\circ}$.
} 
como el turno de representantes de cada una de estas áreas tanto en el oficio de general como en los cargos de mayor relevancia, para con ello «paliar las quejas de algunos monjes, que aseguraban que los cargos más honrosos (...) recaían casi siempre en monjes de una misma región o profesos de determinados monasterios prepotentes $\rangle^{40}$. Estos movimientos parecen derivarse en última instancia de la desigual distribución en el territorio peninsular de los cenobios que componían la Congregación, así como del modo en que se llevó a cabo la reforma de la vieja red de abadías benedictinas en los siglos XV y XVI en todo el cuadrante Noroeste de la Corona de Castilla, que supuso la completa reestructuración del mapa monástico medieval, la pérdida de autonomía para unas casas que hasta entonces habían funcionado con mucha mayor libertad y, sobre todo, la ruptura de las relaciones con una sociedad local que dejó de suministrar nuevos religiosos para sus claustros y que observó cómo son monjes venidos de fuera los que intentan poner a funcionar la maquinaria administrativa con unos usos renovados ${ }^{41}$.

Más allá de estos episodios aislados del siglo anterior, con las consecuencias ya advertidas (adopción de la estructura tripartita), en los primeros años del siglo XVIII la vida en la Congregación pareció discurrir de nuevo con relativo sosiego. Al menos, así fue hasta las décadas de 1730 y 1740 . Entonces, la falta de unanimidad en la elección de fray Miguel de Herze como general y el desajuste en la distribución de las abadías entre los naturales de los tres distritos distintos en los capítulos generales de 1737 y 1741 generaron un clima de descontento en algunos sectores de la Congregación ${ }^{42}$. Unos sectores que veían, además, cómo

\footnotetext{
40 Zaragoza Pascual, Los Generales..., t. IV, pág. 13.

${ }^{41}$ Deben verse las oportunas apreciaciones de Baudilio BARRERIO MALlón, El tabaco y el incienso. Un episodio compostelano del siglo XVII, Vigo, Nigratrea; Consorcio de Santiago, 2009 (Libros da Brétema, 15), págs. 52-53. Sobre las consecuencias sociales y económicas de la reforma en los monasterios benedictinos gallegos pueden verse las síntesis de Ofelia REY CASTELAO, "El clero regular", en José García Oro (coord.), Historia de las diócesis españolas. T. XV: Iglesias de Lugo, Mondoñedo-Ferrol y Orense, Madrid, Biblioteca de Autores Cristianos, 2002, págs. 140-141; Ofelia REY CASTELAO, "El clero regular de la diócesis compostelana en la Edad Moderna", en José García Oro (coord.), Historia de las diócesis españolas. T. XIV: Iglesias de Santiago de Compostela y Tuy-Vigo, Madrid, Biblioteca de Autores Cristianos, 2002, págs. 362-366.

42 Carta aquí editada, párrafo § 4. Ya advertía Álvarez de Miranda que en su dedicatoria del Suplemento del Teatro "alude Feijoo a ciertas tensiones que habían agitado a la congregación benedictina en los comienzos de la prelacía de ese general" (Álvarez DE MirAndA, "Los paratextos...”, pág. 335). En efecto, así dice Feijoo de Herze: “QQué podíamos esperar del amante y benévolo corazón de V. S. Rma. sino este precioso fruto? Digo la apacible tranquilidad que hoy goza toda la Religión. Hubo al principio circunstancias que hicieron temer a algunos que la paz no fuese tan serena en este cuatrienio como en los antecedentes. [...] Pero la dulzura y benevolencia de V. S. Rma., regidas una y otra por una consumada discreción, disiparon luego aquellos miedos; y, en virtud de su benigno influjo, no solo se conservó la unión de los ánimos, mas aun se concilió a un dictamen uniforme (lo que parecía imposible) la contrariedad de opiniones" (FeıJoo, Suplemento..., s. f. [Dedicatoria]). Es más, en un poema dedicado a Herze destaca Feijoo que "Señas tienes de hechicero, / pues se lee en tu semblante / un pacto expreso que hiciste / de no dar disgusto a nadie" (Feijoo, Obras completas. T. VII, Poesía, pág. 264).
} 
por esos mismos años los bernardos castellanos -monjes cistercienses de la Congregación de Castilla- obtenían del pontífice una nueva bula, ahora cuatripartita, para distribuir oficios y abadías en cuatro partidos, toda vez que las divisiones anteriores en dos y tres distritos no habían logrado impedir entre los cistercienses un clima de violencia que había ido ganando en intensidad desde la década de los setenta del siglo anterior y que, amén de otros episodios, estuvo caracterizado por la proliferación de pasquines, libelos y un sinfín de alegaciones en derecho, por la falta de legitimidad de las elecciones determinadas en los capítulos generales, por la desobediencia al abad reformador, por la multiplicación de «monjes fugitivos»y de penas de distinto alcance, etc. ${ }^{43}$.

Feijoo, como sus compañeros de hábito, fue testigo del grotesco espectáculo que protagonizaron los bernardos castellanos y estimaba la bula de cuatripartición que entonces dictaba el papa como una posible solución para aquellos que «por mucho tiempo habían traído conturbados los ánimos» ${ }^{44}$. Sin embargo, entre los suyos, no veía el de Casdemiro gran motivo para alentar la reforma, pues, como consigna en la carta, «ni la más leve apariencia de tal motivo intervino para la distribución nacional, pues estaba enteramente tranquila la religión cuando se empezó a pensar en esta novedad» ${ }^{45}$.

«Esta novedad» fue idea del padre fray Anselmo Mariño, abad general de la Congregación benedictina entre 1741 y 1745, quien, al finalizar su mandato, planteó en sesión de Capítulo General la conveniencia de dividir también la Congregación en cuatro provincias -insistamos: Galicia, Tierra de Campos, La Rioja e Indiferentes-. En esencia, se trataba de modificar la estructura tripartita vigente desde el último tercio del seiscientos, pues estimaba «útil y necesario el señalar a cada monasterio el número de monjes que pudiese sustentar; y que los hábitos fuesen de todos los países a proporción correspondiente; y que los em-

\footnotetext{
${ }^{43}$ La bibliografía sobre las disputas internas en la Congregación cisterciense cuenta con algunos títulos de referencia, pero dista de conocerse con toda la precisión que sería de desear (DOMínGUEZ ORTIZ, $L a$ sociedad española..., t. II, págs. 86-87; José Miguel LóPEZ GARCíA, La transición del Feudalismo al Capitalismo en un señorio monástico castellano. El abadengo de la Santa Espina (1147-1835), Valladolid, Junta de Castilla y León, 1990, págs. 125-131 y 395-430; BARREIRo MALLóN, “Los problemas...”, págs. 20-24; y, últimamente, Guillermo FERNÁNDEZ OrTIZ, "La crisis de los bernardos castellanos según un impreso de la Biblioteca Universitaria de Zaragoza. Estudio y edición”, Cuadernos de Estudios Borjanos, 59 (2016), págs. 135-153). Un volumen facticio conformado por impresos y manuscritos con abundante información sobre el particular se conserva en AMSJS, Fondo San Clodio, Papeles reunidos por el padre Benito Escudero sobre los enfrentamientos de la Religión. Por su parte la Biblioteca Nacional de España conserva un volumen documental también significativo: BNE. Porcones. 15/15; 45/12; 45/14; 61; 70/17; 91/32; 97/38; 99/8; 99/11; 187/8 y 1432/30. En fin, la documentación que para en la sección Consejos del AHN ha sido abundantemente utilizada por José Miguel López García en su estudio sobre el monasterio de La Espina aludido en esta misma nota.

${ }^{44}$ Carta aquí editada, párrafo $\S 4$.

${ }^{45}$ Carta aquí editada, párrafo $\S 3$.
} 
pleos tengan la misma proporción y correspondencia» ${ }^{46}$. Para entonces, Feijoo ya era conocedor del planteamiento de Mariño y, desde un primer momento, le manifestó sus objeciones a la propuesta; objeciones que son las que en esta carta desarrolla por extenso ${ }^{47}$. Como él, otros monjes «de la primera distinción» ${ }^{48}$, tanto en la propia sesión capitular como en años posteriores, expresarían sus reticencias - cuando no su frontal rechazo- a una novedad que no logró colmar sin embargo las ambiciones de todas las regiones. Así, muy pronto se pudieron observar las limitaciones de la nueva partición con la insatisfacción de los asturianos $^{49}$, grupo significativo en el partido de Indiferentes ${ }^{50}$, que vieron cercenadas sus aspiraciones de acceder al generalato en $1761^{51}$.

En esencia, Feijoo lo que se propone «en esta carta [es] representar a vuestra reverendísima, (...) que, aun cuando el gobierno practicado anteriormente trajese algunos inconvenientes (¿y qué gobierno hay que no los tenga?), son mucho mayores los que se siguen del pretendido equilibrio $\rangle^{52}$. Para ello se detiene puntualmente en

\footnotetext{
${ }^{46}$ AMSDS. Fondo Papeles varios manuscritos, signatura 46, fol. 1r.": "En el Capítulo General que la Congregación de San Benito de España celebró el año de 1745, en la sesión que tuvo el día 19 de mayo del mismo año, el reverendísimo padre maestro fray Anselmo Mariño, presidente del Capítulo, propuso ser conveniente, útil y necesario el señalar a cada monasterio el número de monjes que pudiesse sustentar; y que los hábitos fuesen de todos los países a proporción correspondiente; y que los empleos tengan la misma proporción y correspondencia”.

47 "El reverendísimo Mariño, autor de la idea, me la comunicó poco tiempo antes del Capítulo General celebrado el año de cuarenta y cinco; y yo muy luego procuré disuadirle con algunas razones que le propuse sucintamente, porque ya no había espacio para más”. Carta aquí editada, párrafo 2.

${ }^{48}$ De hecho, varios monjes se opusieron en el propio Capítulo General, y aun entre los partidarios no existía total unanimidad en la formulación que debía adoptar la reforma a introducir: Fray Miguel de Herze, su íntimo amigo fray Benito Marín (luego obispo de Barbastro y de Jaen) y fray Antonio Sarmiento y Sotomayor (entonces obispo de Mondoñedo), quien, sin embargo, no rechazaba totalmente la alternativa en el generalato (Zaragoza Pascual, Los Generales..., t. V, págs. 140-141 y 531-532; AMSDS, Fondo Papeles varios manuscritos, signatura 46 , fols. $\left.1 \mathrm{r}^{\mathrm{o}}-\mathrm{v} .^{\circ}\right)$.

49 Zaragoza Pascual, Los Generales..., t. V, págs. 21 y 170-171. El mismo autor trata el particular por extenso en Zaragoza Pascual, "Reivindicación...”, págs. 757-774.

50 "El partido de Indiferentes se compuso de los arzobispados de Sevilla y de Toledo, del obispado de Sigüenza, de las dos Andalucías, de la provincia de Estremadura, del Principado de Asturias, del Principado de Cataluña y Corona de Aragón" (AMSDS, Fondo Papeles varios manuscritos, signatura 46, fol. 1r. ${ }^{\circ}$. Este grupo de "Indiferentes" estaba integrado por 14 monasterios: San Martín y Monserrat de Madrid, Sopetrán, Huete, Sevilla, Guixols, Bages, Montserrat de Cataluña y los asturianos de Corias, Obona, Cornellana, San Vicente de Oviedo, Villanueva de Cangas y Celorio (ZARAgOza Pascual, Los Generales..., t. V, pág. 153).

${ }^{51}$ Esta posibilidad ya la habían apreciado algunos de los capitulares en las sesiones de mayo de 1745: "A los que respondió el reverendísimo Mariño que otros juzgaban ser necesaria esta disposición para evitar el perjuicio que se podría seguir a los naturales de los obispados y provincias que componen los partidos de Rioja y de Indiferentes, porque podría suceder el que todos, o los más de los empleos que corresponden a un partido, se confiriesen a los naturales de una provincia o obispado, con notable perjuicio $/ /{ }^{1 v^{\circ}}$ de los naturales de otras provincias y obispados. Y que este perjuicio se podría disculpar con decir que todo quedaba en el partido" (AMSDS, Fondo Papeles varios manuscritos, signatura 46, fols. 1r. ${ }^{\circ}$-v. $^{\circ}$ ).

${ }^{52}$ Compartía esta opinión con Antonio Sarmiento de Sotomayor (ZARAGOZA PAscual, Los Generales..., t. V, pág. 141).
} 
los cinco aspectos a los que atañe el turno: (1) la alternativa en el Generalato; (2) la distribución de abadías; (3) la división de empleos de cátedra y púlpito; (4) la repartición de oficios de administración de hacienda; y (5) la distribución de hábitos.

Antes de entrar en materia deja claro que las circunstancias aludidas para proceder a la reforma emprendida no le merecían ser causa suficiente para alegar semejante necesidad de cambio. Es más, que una facción estuviese escasamente representada un cuatrienio no suponía inconveniente alguno en tanto que en los siguientes cuatro años, o quizá más tarde, sería otra nación la que habría de verse con un menor porcentaje de oficios y responsabilidades: el tiempo largo es para el benedictino el agente que dicta la normalidad. Es más, «el equilibrio nacional en la forma que se ha introducido es moralmente imposible conservarse sin acarrear gravísimos perjuicios a la religión; y aun estaba por decir sin ponerla en un estado calamitoso», especialmente en lo que conduce al despertar de las pasiones nacionales y a la ruptura de la unidad que significaba la Congregación, el «centro común hacia donde inclinaba a todos la uniformidad de la religión».

El mayor inconveniente que observa en la alternativa del generalato es que no siempre se elegiría al más adecuado, pero en la balanza pone también una ventaja: evitar fricciones entre nacionalidades, pues el General nombrado se cuidará muy mucho de perjudicar al resto de partidos, para evitar que, al tomar el relevo en el gobierno el resto de bandos, sus partidarios salgan entonces malparados. De seguir adelante con la aplicación de la cuatripartita, Feijoo se decantaría por limitarla precisamente a esta alternativa en el generalato, compartiendo parecer, como en otros puntos, con Antonio Sarmiento de Sotomayor ${ }^{53}$.

En la existencia de una cuota nacional para el resto de oficios y responsabilidades sí encuentra un riesgo exagerado, pues «la justicia distributiva respectiva únicamente al mérito» debe prevalecer sobre la igualdad nacional, ya que esto implicaría «desproporcionar muchas veces los empleos a los talentos». El asunto reviste especial gravedad en lo que atañe a cátedras y púlpitos ${ }^{54}$, pero también a aquellos cargos directamente relacionados con el gobierno de las haciendas monásticas y que a juicio del benedictino precisan de talentos si no más elevados, sí sumamente específicos.

En fin, la nueva política de concesión de hábitos en función de la potencia de las regiones no la ve inoperativa y cabe en este punto recordar cómo la patria de los que accedían al noviciado era una información que ya se valoraba con anterioridad a la adopción de la cuatripartita.

En fin, a modo de colofón, podemos concluir estas páginas, con las palabras que escribía Ernesto Zaragoza cuando daba a conocer la existencia de esta carta hace casi medio siglo, párrafos que nuestra edición viene por fin a culminar:

\footnotetext{
53 Zaragoza Pascual, Los Generales..., t. V, pág. 141.

${ }^{54}$ De nuevo comparte parecer con Antonio Sarmiento de Sotomayor. (Zaragoza Pascual, Los Generales..., t. V, pág. 141).
} 
El Padre Feijoo era contrario a la cuatripartita, porque, según manifiesta en carta del 27 de agosto de 1755, con ello se dividían los ánimos, disminuía el amor fraterno y la Congregación semejaba cuatro congregaciones distintas; aseguraba que en los monasterios había tantos grupos como provincias, y que no siempre habia en ellas sujetos preparados para todos los cargos. Sin embargo, se inclinaba por la alternativa en el generalato y en la recepción de los novicios, pero quería que las abadias, cátedras, púlpitos y cargos de administración económica se diesen a los mejor preparados y no por provincias ${ }^{55}$.

\section{TESTIMONIOS}

Trabajamos con tres testimonios de la siguiente carta. Ninguno es autógrafo, pues se trata de tres copias en limpio, las tres procedentes del archivo del monasterio de Santo Domingo de Silos, lo que no resulta extraño, dado que allí fue a parar el Archivo General de la Orden de San Benito, y ya hemos dicho que el texto con que trabajamos se refere de manera muy particularizada al modo de gestión interna de la orden:

\begin{tabular}{|c|c|}
\hline Ms. A & 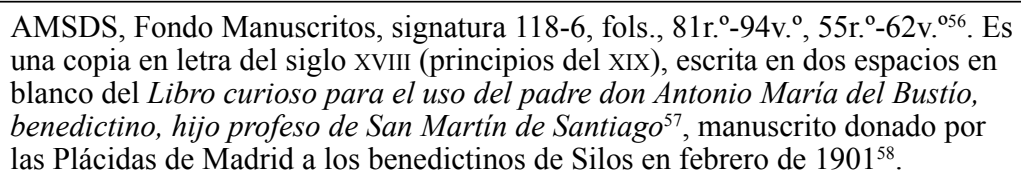 \\
\hline Ms. B & $\begin{array}{l}\text { AMSDS, Fondo Manuscritos, signatura } 54-17 \text {, fols. } 61 \mathrm{r}^{0}{ }^{-}-64 \mathrm{r}^{059} \text {. Es también } \\
\text { copia en letra del siglo XVIII (o principios del XIX), enuadernada en un tomo de } \\
\text { Papeles varios. En su final puede leerse: «Sacose esta copia teniendo presente el } \\
\text { original, escrito todo él de mano y puño de su autor» (fol. } 64 \mathrm{r}^{\circ}{ }^{\circ} \text {. }\end{array}$ \\
\hline Ms. C & $\begin{array}{l}\text { AMSDS, Fondo Papeles varios manuscritos, signatura } 46 \text {, fols. } 11 \mathrm{r}^{\mathrm{0}}-34 \mathrm{v}^{\mathrm{o}} \text {. Nue- } \\
\text { vamente, es copia en letra del siglo XVIII. La carta forma junto con otros papeles } \\
\text { parte de una carpeta titulada Dictámenes y reflexiones sobre la distribución de } \\
\text { oficios en la Congregación de Valladolid. Tal como precisa ya el catálogo de la } \\
\text { institución, «el tercero de ellos es del padre Feijoo» }{ }^{60} \text {. }\end{array}$ \\
\hline
\end{tabular}

\footnotetext{
55 Zaragoza Pascual, Los Generales..., t. V, pág. 150, n. 17.

${ }^{56}$ Miguel C. Vivancos, Catálogo del Archivo del Monasterio de Santo Domingo de Silos, Silos, Abadía de Silos, 2006, pág. 131.

${ }^{57}$ Así consta en la portada monumental del códice (véase Ernesto ZARAGOZA PASCUAL, "Libros de gradas de los monjes de San Martín Pinario de Santiago de Compostela (1502-1833)”, Estudios Mindonienses, 7 (1991), págs. 471-557). Por su parte, el poseedor del manuscrito, Antonio María del Bustío, era Correspondiente de la Real Academia de la Historia, por Madrid, el año 1842, según consta en la Guía de forasteros en Madrid para el año de 1842, Madrid, Imprenta Nacional, [s. a.], pág. 229.

${ }^{58}$ Nota manuscrita al dorso de la portada del códice.

${ }^{59}$ Vivancos, Catálogo..., pág. 228.

${ }^{60}$ Vivancos, Catálogo..., pág. 131.
} 
Finalmente existe noticia de un cuarto testimonio de esta carta en el Archivo Diocesano de Zamora ${ }^{61}$, al que, pese a nuestros esfuerzos, nos ha sido imposible acceder.

\section{EDICIÓN}

Hemos de empezar por declarar que se trata de tres copias en limpio que presentan pocos errores y que se manifiestan bastante próximas entre sí y bastante próximas también al original. Una vez examinados los tres testimonios -remitimos al aparato crítico positivo que disponemos tras la carta-, parece que solo hay un error común en toda la tradición, compartido por los testimonios $\mathrm{A}$ y $\mathrm{C}$, que presentan idéntico desliz al referirse al Capítulo General del año «1745», cuando de la lógica del discuso se desprende que solo pueden estar aludiendo al de «1737»:

\begin{tabular}{|c|c|c|c|}
\hline A, C & B & Texto crítico & Localización \\
\hline año de 45 & año de 37 & año de 37 & $\S 4$ \\
\hline
\end{tabular}

Asimismo, está claro que A y C no se copian entre sí y descienden de un subarquetipo en ramas separadas, pues presentan errores cruzados:

1. Errores de A respecto de $\mathrm{C}$ :

\begin{tabular}{|c|c|c|c|}
\hline A & C & Texto crítico & Localización \\
\hline modo & Motivo & motivo & $\S 3$ \\
\hline prensa & Prendas & prendas & $\S 4$ \\
\hline había habido & habrá habido & habrá habido & $\S 7$ \\
\hline quejoso & Quejosa & quejosa & $\S 12$ \\
\hline $\begin{array}{c}\text { muchas ocasiones la } \\
\text { consideración }\end{array}$ & $\begin{array}{c}\text { muchas ocasiones pre- } \\
\text { ferir la consideración }\end{array}$ & $\begin{array}{c}\text { muchas ocasiones pre- } \\
\text { ferir la consideración }\end{array}$ & $\S 25$ \\
\hline
\end{tabular}

2. Errores de $\mathrm{C}$ respecto de $\mathrm{A}$

\begin{tabular}{|c|c|c|c|}
\hline A & C & Texto crítico & Localización \\
\hline $\begin{array}{c}\text { Nuestra Señora del } \\
\text { Bueso }\end{array}$ & $\begin{array}{c}\text { Nuestra Señora del } \\
\text { Hueso }\end{array}$ & $\begin{array}{c}\text { Nuestra Señora del } \\
\text { Bueso }\end{array}$ & $\S 7$ \\
\hline $\begin{array}{c}\text { comunísimo repa- } \\
\text { rarse }\end{array}$ & comunísimo reparse & $\begin{array}{c}\text { comunísimo repa- } \\
\text { rarse }\end{array}$ & $\S 8$ \\
\hline
\end{tabular}

\footnotetext{
${ }^{61}$ Da noticia del mismo, sin precisar su signatura, Zaragoza Pascual, Los Generales..., t. V, pág. 150 (n. 17); se refirió también a este testimonio, de nuevo sin datos concretos, ZARAGOZA PASCUAL, "Reivindicación...”, pág. 765, n. 18.
} 
Igualmente, aunque no pueda hablarse de error, también separa a A y C el hecho de que este último testimonio no presente firma ni fecha de la carta.

Por su lado, el testimonio B discurre por otra rama, tendida esta directamente desde el origial, lo que avalan nuestros cotejos y también los datos externos de que disponemos, ya que no hemos de olvidar que B declara expícitamente estar siguiendo el autógrafo feijoniano - «Sacose esta copia teniendo presente el original, escrito todo él de mano y puño de su autor» (fol. 64r. ${ }^{\circ}$ )-. No obstane, ello no quiere decir, ojo, que $\mathrm{B}$ no incluya algún error propio respecto de $\mathrm{A}$ y $\mathrm{C}$ :

\begin{tabular}{|c|c|c|c|}
\hline A, C & B & Texto crítico & Localización \\
\hline En ellas & En ella & En ellas & $\S 13$ \\
\hline Se hacen más visibles & Se han más visibles & Se hacen más visibles & $\S 14$ \\
\hline Igualar en ella & Igualar ellos & Igualar en ella & $\S 15$ \\
\hline
\end{tabular}

El estema, por tanto, queda como sigue:

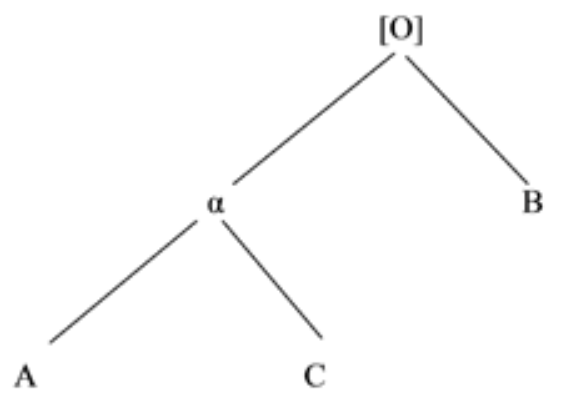

Se trata de un estema muy útil a la hora de examinar las variantes adiáforas para fijar el texto, porque toda coincidencia de A con B o de C con B arroja el texto que debe editarse por aplicación de la ley de la mayoría. El estema solo será inútil en los casos de lectura de $\mathrm{A}$ y $\mathrm{C}$ frente a $\mathrm{B}$, lo que sucede en los siguientes casos:

\begin{tabular}{|c|c|c|c|}
\hline A, C & B & Texto crítico & Localización \\
\hline $\begin{array}{c}\text { conveniencias e } \\
\text { inconvenientes }\end{array}$ & $\begin{array}{c}\text { conveniencias o } \\
\text { inconvenientes }\end{array}$ & $\begin{array}{c}\text { conveniencias e } \\
\text { inconvenientes }\end{array}$ & $\S 1$ \\
\hline notable inmutación & notable mutación & Notable mutación & $\S 2$ \\
\hline para su sucesor & para sucesor & para su sucesor & $\S 4$ \\
\hline $\begin{array}{c}\text { y no sé si también de } \\
\text { otros oficios }\end{array}$ & $\begin{array}{c}\text { y no sé si de otros } \\
\text { oficios }\end{array}$ & $\begin{array}{c}\text { y no sé si también de } \\
\text { otros oficios }\end{array}$ & $\S 5$ \\
\hline $\begin{array}{c}\text { Abunde mucho más } \\
\text { de }\end{array}$ & $\begin{array}{c}\text { Abunde de mucho } \\
\text { más de }\end{array}$ & $\begin{array}{c}\text { Abunde mucho más } \\
\text { de }\end{array}$ & $\S 15$ \\
\hline por evitar & para evitar & por evitar & $\S 17$ \\
\hline Acuérdome de que & Acuérdome que & Acuérdome de que & $\S 20$ \\
\hline
\end{tabular}


En virtud de nuestro estema, pues, nos sentimos legitimados para elegir adiáforas de una $\mathrm{u}$ otra rama. Las elecciones quedan en todo caso muy claras, pues el cuadro que ofrecemos es exhaustivo, dado que las divergencias entre los testimonios son, como se ha dicho, escasas cualitativa y cuantitativamente.

Por lo demás, actualizamos puntuación y ortografía e incluimos las notas necesarias para que el contenido de la carta resulte comprensible, pues, no en vano, se refiere a una serie de pormenores bastante técnicos de la gestión interna de la orden benedictina.

\section{Edición crítica}

\section{CARTA DE NUESTRO REVERENDÍSIMO PADRE MASTRO FEIJOO AL REVERENDÍSIMO Lasanta, General de la Congregación de SAN Benito de Valladolid, SOBRE LA PROVIDENCIA DE LA CUATRIPARTITA}

1. Habiendo yo significado como incidencia de una de las conversaciones que tuve con vuestra reverendísima durante la visita de este colegio ${ }^{62}$ que había hecho varias reflexiones sobre las conveniencias e inconvenientes que era natural produjese la providencia tomada pocos años ha de distribuir los empleos de la orden dando a cada nación o provincia de nuestra península la cantidad correspondiente a los monasterios que sustenta su territorio, me respondió vuestra reverendísima que no sería importuno que yo expusiese por escrito dichas reflexiones, porque podría convenir tenerlas presentes para, por medio de algunas bien meditadas modificaciones, promover las conveniencias o precaver los inconvenientes que pueden resultar de la expresada distribución, en cuya consecuencia resolví representar a vuestra reverendísima cuanto he pensado sobre la propuesta materia.

2. El reverendísimo Mariño ${ }^{63}$, autor de la idea, me la comunicó poco tiempo antes del Capítulo General celebrado el año de cuarenta y cinco; y yo muy luego procuré disuadirle con algunas razones que le propuse sucintamente, porque ya

\footnotetext{
${ }^{62}$ Se refiere a la visita de fray Vitores de Lasanta al colegio de San Vicente de Oviedo. No han llegado a nosotros las visitas, que debían conservarse en el Archivo de la Congregación de San Benito de Valladolid, según Zaragoza Pascual advertía ya (Zaragoza Pascual, Los Generales..., t. V, pág. 163). No hemos podido determinar la fecha exacta de la visita a Oviedo; se conserva en AMSPO (Caja 11, documento 33, fol. 18 r. $^{\circ}$ y ss.) la que hizo el padre Lasanta al monasterio de San Pelayo de la misma ciudad, pero lamentablemente, dado su fragmentario estado de conservación, no consta la fecha en que se efectuó la misma. ${ }^{63}$ Fray Anselmo Mariño (Sahagún, †1747). Natural de Batallanes (diócesis de Tui), profesó en el monasterio de Sahagún en 1702. Fue lector de Artes en Irache (1717-1721), lector de Tercia en San Vicente de Salamanca (1721-1723), regente en el colegio de Eslonza (1723-1725) y abad en Sahagún y Eslonza (1733-1737). Ocupó el generalato de la Congregación entre 1741 y 1745 (véase Miguel C. VIVANCOS, "Mariño, Anselmo", Diccionario Biográfico de la Real Academia de la Historia [en línea], disponible en <http://dbe.rah.es/biografias/56174/anselmo-marino> [Consulta: 23/05/2020]; y ZARAGOZA PASCUAL, Los Generales..., t. V, págs. 5 y 147-150).
} 
no había espacio para más, pero en substancia las mismas que ahora con alguna mayor especificación voy a exhibir.

3. La primera, fundada en la ninguna necesidad que había de introducir tan notable mutación en nuestro gobierno, en el cual cualquiera grande novedad pide grande motivo, como en efecto le hubo en una $u$ otra religión en que se estableció la distribución de prelacías y otros empleos por naciones, no habiendo hallado otro medio de atajar altercaciones y contiendas que por mucho tiempo habían traído conturbados los ánimos ${ }^{64}$. Ni la más leve apariencia de tal motivo intervino para la distribución nacional, pues estaba enteramente tranquila la religión cuando se empezó a pensar en esta novedad.

4. Bien sé que uno u otro quisieron pretextarla con lo que pasó en el capítulo del año 37, ¿y qué hubo en aquel capítulo de particular más que en otros? Que la mayor parte de los vocales no se conformó con la propuesta que hizo el reverendísimo general para su sucesor ${ }^{65}$. Pero aun prescindiendo por ahora de si hubo en aquella ocasión algún especial motivo para disentir a la propuesta del general (como en sentir de muchos realmente le hubo), ¿qué hicieron en esto los vocales sino usar de la libertad que les concedían y aun prescribían los sagrados cánones?, ¿por ventura el conformarse con la propuesta era cosa de precepto ni aun de consejo? El hecho fue que la mayor parte de los vocales eligieron un sujeto tan digno, tan condecorado, de tan espectable sabiduría y virtud que nadie, aun de los más afectos al general, se atrevió a decir (creo que ni aun a pensar) que el propuesto por este excediese ni un átomo en las prendas proprias para el gobierno al que eligió la congregación ${ }^{66}$. Es, pues, sin duda, impertinente el recurso a lo que sucedió en el Capítulo del año de 37 para pretextar la gran novedad de la repartición por naciones.

5. Pero los más recurrieron a otro pretexto para la introducción de dicha novedad, que fue haber quedado mejorada cierta nación respecto de las demás

\footnotetext{
${ }^{64}$ Alusión inequívoca a las disensiones y disturbios que se sucedieron en el seno de la Congregación cisterciense de Castilla desde mediados del siglo XVII hasta muy avanzado el siglo XVIII. El último en abordar el estudio de esta cuestión, FernÁNDEZ ORTIZ, "La crisis...”, págs. 135-153. Además, pueden verse los títulos citados en la n. 43 del presente trabajo.

${ }^{65}$ La elección de General aparece minuciosamente reglamentada en las Constituciones de la Congregación: Constituciones de la Congregación de nuestro glorioso padre San Benito de España e Inglaterra, Madrid, Viuda de Melchor Álvarez, 1706, capítulo VII. Sobre este asunto parece haber tratado precisamente por escrito con el padre Sarmiento (ARIAS, "Catorce cartas...”, págs. 31-32).

${ }^{66}$ Fray Miguel de Herze fue elegido General de la Congregación en sesión capitular de 21 de mayo de 1737. Sin entrar en precisiones sobre su nombramiento como General sí ofrece una semblanza amplia, Ernesto Zaragoza PASCUAL, "Fray Miguel de Herze, un calagurritano ilustre y desconocido", Kalakorikos, 9 (2004), págs. 257-272. Como General dio la licencia de impresión del tomo octavo del Teatro crítico (1738) y al Suplemento (1740), según preceptuaban las constituciones de la Congregación: Constituciones..., 1706, pág. 111. En los mismos términos en los que Feijoo se expresa en esta carta ya se había manifestado en la dedicatoria que le hace en 1740 (FeIJoo, Suplemento..., s. f. [Dedicatoria]).
} 
en los dos capítulos anteriores al del año de 45 en la distribución de prelacías, y no sé si también de otros oficios, haciendo más reparable esta desigualdad la circunstancia de ocupar dicha nación menos territorio y sustentar menor número de monjes que otras que fueron mucho menos atendidas.

6. Ni este motivo tiene más subsistencia que el antecedente, porque, prescindiendo por ahora de la causa que hace inevitable que muchas veces no se distribuyan las prelacías con proporción al tamaño de los monasterios o número de monjes que sustenta cada nación -la cual causa se expondrá más abajo cuando se trate de los inconvenientes anexos a la nueva providencia-, varias veces se han practicado semejantes desigualdades, y aun mayores que la que ahora se vocea, sin perjuicio o daño notable de la religión. Esa misma nación cuyas ventajas obtenidas en los dos capítulos anteriores al del año de 45 se clamorean ahora, en el que se celebró el año primero de este siglo quedó tan deteriorada, que en la distribución de prelacías no le tocó sino la más pobre y estrecha de toda la Orden (la de Nuestra Señora del Bueso ${ }^{67}$, en Castilla la Vieja, que, cuando más, con mucha angustia sustenta tres monjes), sin que sus quejas conturbasen la religión ni hiciesen ruido fuera de ella.

7. Es verdad que veinte años antes otra nación había dado no solo igual pero aun más ilustre ejemplo de moderación o de paciencia en la misma materia; más ilustre, digo, porque, siendo mucho mayor su población y sustentando en su territorio mucho mayor número de monjes, no le tocó en la distribución capitular más que la misma pobrísima abadía de Nuestra Señora del Bueso, sin que los quejosos hiciesen el menor movimiento a tumulto o sedición, de modo que ni dichas desigualdades ni otras muchas que verisímilmente habrá habido en otros capítulos anteriores, alteraron poco o mucho la tranquilidad de la religión ni impidieron que en ella floreciese la observancia y el cultivo de las letras; y, así, a nadie pasó por el pensamiento ser necesario para el buen gobierno de la religión el equilibrio nacional que se introdujo el año de 45; luego, igualmente y aun más superfluo sería ahora, cuando la desigualdad con que se pretende motivar fue sin comparación menos notable que las mencionadas.

$8 \mathrm{El}$ caso es que el equilibrio nacional en la forma que se ha introducido es moralmente imposible conservarse sin acarrear gravísimos perjuicios a la religión; y aun estaba por decir sin ponerla en un estado calamitoso. Y esto es

\footnotetext{
${ }^{67}$ Tras haber sufrido un incendio, en 1725 se había propuesto en Capítulo General su reducción en priorato, a causa de sus pocas rentas, y aún años después (1761) se propondría su supresión, destinando sus exiguas rentas a Santo Toribio; informaciones similares sobre la entidad de la abadía no son extrañas en todo el siglo XVIII (ZARagoZa PASCuAL, Los Generales..., t. V, págs. 116, 126, 132, 175 y 185). Sobre la historia de la abadía es de interés Ernesto Zaragoza PASCuAL, "Abadologio del monasterio de Nuestra Señora de la Anunciación del Bueso (1460-1789)", Investigaciones Históricas. Época Moderna y Contemporánea, 21 (2001), págs. 19-45, donde ofrece estas y otras informaciones.
} 
lo que principalmente me propongo en esta carta representar a vuestra reverendísima, de modo que, aun cuando el gobierno practicado anteriormente trajese algunos inconvenientes (¿y qué gobierno hay que no los tenga?), son mucho mayores los que se siguen del pretendido equilibrio, y así viene a ser este remedio una enfermedad, o causa de ella, mucho peor que la que se piensa curar con él, porque esta realmente es o será una enfermedad del todo de la Religión, como procuraré luego demostrar, cuando de la desigual repartición entre las provincias solo se puede seguir el menoscabo solitario de una u otra porción de ella. ¿Y qué inconveniente es para el todo de la orden que en uno u otro capítulo esta nación obtenga uno o dos oficios menos y aquella uno u dos más de los que corresponden al número de sus monasterios? Levísimo, sin duda, mayormente si se considera que es comunísimo repararse esta desigualdad, si no en el capítulo inmediato subsiguiente, en otro poco distante. Así sucedió hasta ahora, por lo que ninguna nación logró por largo espacio de tiempo alguna ventaja sobre las otras. Y es verosímil que, sin hacer novedad substancial en el govierno, siempre en adelante sucediese lo mismo.

9. El ideado o entablado equilibrio tiene cinco partes o ramos: el primero es la disposición de la alternativa del generalato por naciones; el segundo, la distribución de abadías respectivamente a las mismas; el tercero, la división de empleos en cátedra y púlpito; el cuarto, la repartición de oficios de administración de hacienda; el quinto, la distribución de los hábitos. Discurriré, pues, lo primero sobre el inconveniente y disonancia que tiene la repartición por naciones considerada en su totalidad para anotar después lo que tiene de malas secuelas cada ramo de por $\mathrm{si}^{68}$.

10. Esta división de los empleos por provincias, señalando a cada uno su cuota, cualquiera que la considere con la atención debida hallará que trae consigo por secuela cierta división de los ánimos. Con ella se nos hace presente a cada nueva provisión de oficios la patria donde nacimos, que es lo mismo que acordarnos de lo que principalmente deberíamos tener olvidado ${ }^{69}$. Harto daño hace al bien público en cualquiera especie de gobierno aquella pasión con que cada individuo mira por sí mismo ¿Qué sería si a esta se añade el de la pasión nacional $^{70}$ ? Esto es en realidad dar más extensión a la esfera del amor proprio.

\footnotetext{
68 En la Congregación cisterciense de Castilla, afecta al conjunto de oficios de entidad y al reparto de nuevos hábitos. Difiniciones cistercienses de la Sagrada Congregación de San Bernardo y Observancia de Castilla, Valladolid, Viuda de Santander, 1786, págs. 6, 7, 8 y 139 (caps. 1 y 25).

${ }^{69}$ Con la profesión el nuevo monje abandonaba el siglo y con ello su nombre de pila en favor de su nuevo nombre en religión. Al mismo tiempo pasaba a ser hijo de la casa matriz en la que tomaba el hábito.

${ }^{70}$ La expresión pasión nacional ya había sido utilizada por Feijoo en 1729 (Benito Jerónimo FEIJoo, Teatro crítico universal, t. III, Madrid, Francisco del Hierro, 1729, pág. 212) con idéntica connotación. Esa expresión ha sido estudiada en el trabajo clásico de Pedro Álvarez de MiRANDA, Palabras e ideas. El léxico de la Ilustración temprana en España, Madrid, Real Academia Española, 1992, págs. 237-238.
} 
Todos los que tienen un mediano conocimiento del corazón humano saben que a cuanto mayor número de objetos profanos se distrae su afecto, tanto más se minora o debilita el que debe a las obligaciones que le proponen las leyes.

11. Pero el peor y más sensible efecto de dicha división tomada en general, aunque en cierto modo coincide con el que acabo de explicar, es la quiebra que induce en el amor fraterno entre los individuos de diferentes provincias, que, como pertenecientes a distintos cuerpos, ya no pueden considerarse tan hermanados como antes. Hasta ahora no había más que un centro común hacia donde inclinaba a todos la uniformidad de la profesión. Ahora, demás de ese centro común, hay otros centros particulares que debilitan o quiebran el movimiento que conducía hacia aquel.

12. Había antes no más que una congregación; ahora está dividida en cuatro como congregaciones subalternas con derechos separados, al modo de los cantones helvéticos, de las ciudades anseáticas o de los palatinados polacos. ¿Qué ha sido esto sino transformar la congregación en disgregación o por lo menos hacer una mal compacta mezcla de uno y otro? Sin violencia también se podrá llamar dilaceración moral de este cuerpo místico y aplicarse a sus autores aquel comminatorio gemido de la majestad divina en la pluma de Jeremías: «Vae pastoribus qui disperdunt et dilacerant gregem pascuae meae!» ${ }^{71}$. O la intimación de aquella terrible protesta por boca del profeta Joel: «Disceptabo cum eis super populo meo et haereditate mea Israel, quos disperserunt in Nationibus et terram meam diviserunt ${ }^{72}$. Y aunque el sentido literal y primitivo de este texto es respectivo a la dispersión del pueblo judaico que antes de la venida de Cristo hicieron los caldeos, tirios, idumeos y otras gentes, es bien claro que con bastante propriedad se puede aplicar a la dispersión que entre nosotros introdujo la nueva providencia y que podemos representarnos que la majestad divina estará al presente quejosa de esta, como un tiempo se quejó de aquella.

13. Dispersión por naciones es realmente la partición de los empleos por provincias y esta ocasiona otra dispersión, también nacional, harto disonante y que sin mucho arrojo se podría cualificar de algo escandalosa. Muchos han notado que en algunas comunidades tanto cuanto numerosas, en aquellas horas en que la ley permite el recreo de la conversación, es harto frecuente gozar los monjes este alivio separados en distintos globos, por no llamarlos corrillos, aquí los de esta provincia, allí los de aquella, acullá los de la otra. Estas parciales uniones en pequeños trozos nacionales, ¿qué son sino un visible destrozo de la unión y amor fraterno que debe reinar en el todo de la religión y en el de cada comunidad?

\footnotetext{
71 Jeremías, 23, 1: “Ay de los pastores que dispersan y extravían las ovejas de mi rebaño!”.

${ }^{72}$ Joel, 4, 2: "Las juzgaré por sus delitos contra mi pueblo y heredad, porque dispersaron a Israel por las naciones, se repartieron mi tierra".
} 
¡Cuán naturales son en ellas las tímidas reservas, las recíprocas desconfianzas entre los individuos que componen diferentes partidos! ¡Y aun las sospechas de mutuas detracciones y censuras!

14. Discurriendo ahora por los diferentes ramos de la división, creo se hacen más visibles en ellos y más graves los inconvenientes, a excepción de la alternativa del generalato, porque, aunque hay en ella un inconveniente de bastante peso, hay para contrarrestarle una compensación muy apreciable. El inconveniente es que en la mayor parte de los capítulos no se eligirá el más digno. La razón es clara: porque es más verosímil hallarse el más digno en el cúmulo de los tres partidos que para este oficio se descartan que en aquel único a quien toca por la alternativa. Mas, como he dicho, para este inconveniente hay una compensación de grande utilidad y es que con dicha alternativa, excluida la de abadías y otros empleos, fácilmente se repara el detrimento que en cualquiera capítulo puede padecer esta o aquella nación, siendo manifiesto que a cualquiera general cuya pasión inclina a cargar el peso de su auroridad para que quede su nación mejorada en las abadías y otros oficios, servirá de freno el ver que en los capítulos siguientes podrán tener su desquite las naciones que en su capítulo quedaron deterioradas, cuya compensación tanto más bien recibida será cuanto la repartición antecedente, por no ser conforme a la equidad, se hizo odiosa. Y cuando esta consideración no reprima el afecto apasionado de uno u otro General, el remedio de la compensación siempre queda libre a los sucesores.

15. En que también ocurre otra advertencia dignísima de reparo, y es que, repartiéndose las prelacías y oficios de honor y literatura sin respecto al número de los nacionales, sí solo atendiendo al mérito de los individuos en la colección de los cuatro partidos, habrá más copia de sujetos dignos del generalato que entrando a la parte con el mérito personal para aquella distribución la mira de igualar en ella las naciones. Porque, por ejemplo, como Dios, supremo dueño de todo, no está obligado a repartir los dones de la naturaleza o de la gracia con proporción al mayor o menor territorio de las naciones, ni al mayor o menor número de los individuos que las componen, sucederá algunas veces que una provincia de más estrecho territorio y más limitado número de individuos abunde mucho más de sujetos bien dotados en una y otra línea que otra provincia de muy mayor población. Efectivamente, en menos espacio que el de un siglo, se vieron algunas de estas desigualdades. Lo que resultará, pues, necesariamente es que, en tales casos, continuándose la nueva providencia, quedarán arrinconados algunos, acaso muchos sujetos de la nación menos populosa, pero más bien surtida en prendas de los particulares; y de la más populosa, pero más escasa de sugetos hábiles para llenar el número de empleos correspondiente a la nación, se colocarán en ellos sujetos ineptos, supliendo con ellos la penuria de los aptos. Sobre cuyo supuesto se puede hacer 
el cómputo prudencial de que dentro de veinte o treinta años estará pobrísima la religión de hijos proporcionados a los empleos que tiene que proveer, desde el generalato hasta los oficios de administración de hacienda, daño horrible que enteramente se evitaría reduciendo la repartición por provincias únicamente al generalato, cuya alternativa al mismo paso impediría el que alguna nación lograse predominio considerable sobre las otras.

16. Descendiendo del generalato a los demás oficios, ninguno veo en que la partición nacional no esté expuesta al riesgo expresado. De modo que, para entablar la igualdad nacional sin perjudicar a la justicia distributiva respectiva únicamente al mérito, sería menester establecer antes con Dios que repartiese el mérito con igualdad entre los cuatro partidos o nacionalidades, como las llama la Bula apostólica ${ }^{73}$. Mas como esta convención no solo es quimérica, más aun sería insolencia solicitarla con nuestros ruegos, subsistirá siempre, continuándose la práctica de la nueva providencia el riesgo de desproporcionar muchas veces los empleos a los talentos.

17. Convengo en que es posible el caso de que la prudencia dicte tragar este inconveniente, aunque gravísimo, por obviar otros mayores, como en efecto así ha sucedido en una u otra religión en que no se halló otro modo de terminar pleitos prolijos y escandalosos ${ }^{74}$. Pero no habiéndose hallado jamás nuestra religión en ese apuro, antes bien, siempre distantísima de él, pues nunca hubo el más leve asomo de alteración o litigio por intereses nacionales, es claro que no hubo motivo para la nueva providencia. Y, así, el introducirla fue exponer sin necesidad alguna la religión a los gravísimos inconvenientes propuestos. Y si se me quisiese decir que este fue un remedio precautorio para evitar el mal en adelante, replico, lo primero, que ningún médico prudente usa de remedios precautorios para evitar una enfermedad meramente posible, mucho menos si los remedios son violentos y peligrosos, cual lo es el de la presente cuestión, pues esto viene a ser estragar la salud que de presente se goza por evitar una enfermedad de que no hay la más leve amenaza. Replico, lo segundo, que la experiencia de haberse mantenido la religión en paz por el largo espacio de casi dos siglos con el sistema de gobierno entablado por la santidad de Paulo V en la sentencia que dio a favor de la Congregación contra el monasterio de San Benito de Valladolid, fundaba una probabilísima esperanza de que, manteniéndose el

\footnotetext{
${ }^{73}$ Es cierto que en otros textos coetáneos el documento pontificio es denominado "breve", pero el discurso diplomático adopta inequívocamente la estructura de las litterae solemnes, denominadas laxamente bulas desde el siglo XVI. Sobre estos tipos documentales deben verse los trabajos ya clásicos de Paulius Rabikauskas, Diplomática pontificia, Roma, Editrice Pontificia Università Gregoriana, 1980 (4. ${ }^{\mathrm{a}}$ ed.) y Thomas Frenz, I documenti pontifici nel medioevo e nell'etá moderna, El Vaticano, Scuola Vaticana di Paleografia, 1989.

74 V. n. 64 del texto.
} 
mismo sistema, se gozaría la misma quietud ${ }^{75}$. Y, así, el miedo de la perturbación de la paz, que los autores de la nueva idea para fundarla procuraron difundir en la Congregación, fue un terror puramente pánico que solo pudo hacerse lugar en corazones sumamente tímidos. Y se puede creer que este terror pánico tuvo gran parte en el informe que se hizo a nuestro santísimo padre Benedicto XIV para obtener ${ }^{76}$ la Bula de repartición nacional siendo totalmente inverosimil que una exposición sencilla del estado tranquilo de la orden, desnuda de toda exageración, moviese a su Santidad a una innovación tan grande, y mucho menos si se le hubiesen representado los graves inconvenientes que naturalmente se subseguirían a dicha innovación ${ }^{77}$.

18. La imminente diminución del número de sujetos aptos para los oficios inferiores al generalato que he representado como secuela de la nueva providencia es más visible en los de literatura, quiero decir, cátedras y púlpitos. ¿Quién no ve que en diferentes tiempos nos ofrecen diferentes provincias muy desigual número de sujetos hábiles para aquellas dos líneas? Conque, atendiendo únicamente a igualar en los empleos de ellas a las naciones, es consiguiente que por lo común queden retirados de esos empleos algunos sujetos muy proporcionados a ellos e introducidos muchos que no lo son. De que se infiere que es muy probable suceder que dentro de seis u ochos quatriennios estén casi todas las plazas literarias ocupadas por sujetos desproporcionados para ellas.

19. Y lo peor, padre reverendísimos, es que de la decadencia en la literatura es ordinaria secuela la caída de la observancia, como observó nuestro grande historiador y crítico el padre don Juan de Mabillon, coligiendo en su excelente tratado de los Estudios monásticos repetidos ejemplares que lo persuaden ${ }^{78}$,

\footnotetext{
75 Se refiere Feijoo al Motu proprio de Pablo V, fechado en Roma a 1 de septiembre de 1609. El texto íntegro abría, como no podía ser de otro modo, el libro de las constituciones. Constituciones..., 1706, págs. 6-11.

${ }_{76}$ En el manuscrito A puede leerse al final de este folio: "Nota: el que leyere esta carta podrá ver su continuación al folio 55, adonde empieza desde aquella cláusula y se puede creer etcétera", que consta subrayada en el propio manuscrito. El pasaje desde "y se puede creer" hasta "para obtener" se puede leer tanto en la hoja 55 como en la 94.

77 Se trata de la bula de 24 de marzo de 1749, Benedictus Papa XIV ad futuram rei memoriam. Nuper pro parte Dilectorum Filiorum Abbatis Generalis, \& Monachorum Congregationis Vallisoletanae Ordinis Sancti Benedicti Congegationi Venerabilium Fratrum nostrorum Sanctae Romanae Ecclesiae Cardinalium negotiis, \& consultationibus Episcoporum, \& Regularium praepositae exposito, quod anno 1745, Romae, Typographia Reverendae Camerae Apostolicae, 1749. Según el CCPB hay ejemplar de la misma en el AHN de Madrid (Biblioteca auxiliar) y en la Biblioteca de San Millán de la Cogolla.

78 Se refiere a los dos tomos del Traité des études monastiques (1691-1692) -con traducción en Madrid, Viuda de Mateo Blanco, 1715, 2 vols.- de Dom Jean Mabillon (1632-1707), uno de los máximos eruditos de la orden benedictina y modelo constante de Feijoo, quien lo citó en numerosísimas ocasiones (Gaspard DelPy, Bibliographie des sources françaises de B. Feijoo, París, Hachette, 1936, pág. 24).
} 
como así mismo otros muchos en que se vio seguirse al restablecimiento de la literatura el restablecimiento de la observancia ${ }^{79}$.

20. En cuanto a los oficios de administración de hacienda, juzgo que de la distribución de ellos por la proporción precisamente al número de los nacionales, se siguen iguales perjuicios a la religión que los insinuados arriba respecto de las demás clases. No administrando rectamente los bienes de los monasterios, estos irán a menos cada día; por consiguiente, no habrá con qué sustentar a escolásticos ni predicadores y mucho menos el número de monjes que indispensablemente exige el culto divino según la magnitud y dotación de cada monasterio. Acuérdome de que, habiendo tocado yo este punto en conversación a un sujeto grave de la orden, cuyos dictámenes morales y políticos venero, me respondió que para el ministerio de administración de hacienda bastaba cualquiera capacidad, por corta o moderada que fuese, y así cualquiera de los cuatro partidos ofrecería para dicho ministerio la cantidad de sujetos hábiles correspondiente al número de sus nacionales, sucediendo lo contrario en los oficios de literatura, que piden especial ingenio y habilidad.

21. Yo convengo en que si se habla de aquella capacidad intelectual que consiste en la perspicacia o sutileza de ingenio necesaria para hacer progresos en las ciencias o facultades de mera teoría, poco o nada se necesita de esta para administrar oportunamente la hacienda. Pero, ¿no hay otra especie de talentos o prendas útiles para todo gobierno económico? La aplicación, la actividad, la vigilancia, el celo del bien público, la indiferencia hacia los intereses personales, el proceder dulce y urbano con las personas con quienes es preciso tratar, la tolerancia de los importunos o injustamente quejosos, junta con la constancia necesaria para resistirlos, el discernimiento para precaver los fraudes, el modo oportuno de descartar estafadores y parásitos, el tiento en los gastos para no declinar ni al extremo de la sórdida mezquindad ni al de la vana profusión, la robustez y buena salud para sufrir algunos trabajos corporales indispensables en varias ocasiones, $y$, en fin, aquella facultad del alma que llamamos genio y es

\footnotetext{
79 Jean Mabillon, Tratado de los estudios monásticos, t. I, Madrid, Viuda de Mateo Blanco, 1715. Los pasajes que podrían aducirse son numerosos, pero bastan los ejemplos citados a continuación (tomados de los capítulos VIII y IX) para observar la inequívoca vinculación entre la exposición feijoniana y las ideas del maurino, "Cuando este estudio ha aflojado en los monasterios, se ha visto que se ha seguido la distracción, los vanos entretenimientos y el comercio con el mundo; y de aquí se ha originado la total ruina del espíritu monástico. Esto es lo que ha notado la mayor parte de los que han tratado de la decadencia de la Orden de San Benito"; o "Hemos visto que los estudios de las letras eran parte de la observancia en los monasterios de Italia y de Inglaterra. Lo mismo se puede ver en los de Francia". No pensaba de forma muy diferente Martín Sarmiento; sobre el particular hay estudio de Michel DuBuIs, "Virtud y letras. Fray Martín Sarmiento aboga por la implicación a la lectura y al estudio en la congregación de Valladolid", en Silos. Un milenio. Actas del Congreso Internacional sobre la Abadia de Santo Domingo de Silos, t. III, Burgos, Universidad de Burgos, 2003, págs. 589-600.
} 
como esencial para el acierto en todas las cosas, así de teoría como de práctica. Todo esto, ¿no es menester que concurra, en más o menos grados, para formar un buen oficial de hacienda? Y este complejo de cualidades de alma y cuerpo, ¿es tan común que no haya la misma desigualdad en los hombres en orden a ellas que en orden a aquellas virtudes intelectuales que prestan la aptitud para las ciencias? La constitución del mundo es tal, que en todas profesiones y ejercicios constituyen el mayor número los visiblemente defectuosos; el menor, los medianamente proporcionados; reduciéndose por lo común a la unidad o al cero los eminentes. Así, padre reverendísmo, tengo por cierto que si los oficios de hacienda se reparten sin otra regla que la que se toma del número de nacionales, no solo no habrá con qué sustentar los monjes, mas ni aun con qué mantener las paredes de los monasterios.

22. Solo me resta ya hablar del último miembro de la repartición nacional, que es la de los hábitos. Y confieso que en esta parte no hallo reparo de entidad que proponer, siendo justo que cada nación goce de los bienes espirituales y temporales de la orden a proporción del número de religiosos que sustentan las producciones de su territorio, o la industria y trabajo de sus habitantes. Es verdad que no siempre, ni aun por la mayor parte, se podrá guardar en esto una igualdad matemática, siendo imposible observar en las reclutas de religiosos la misma puntualidad que en las de soldados. Así, será preciso en algunos casos dejar al celo y prudencia de generales y abades el arbitrio de moderar por epiqueya ${ }^{80}$ la regla de partición nacional, de modo que nunca hallen la puerta del monasterio abierta ni los pretendientes totalmente inútiles, ni cerrada los de prendas muy sobresalientes.

23. Recapitulando ahora todo lo dicho, resultan las conclusiones siguientes:

1. ${ }^{\text {a }}$ Que la alternativa del generalato, aunque no carece de todo reparo, se puede reputar absolutamente conveniente; y que con ella sola, sin innovar cosa alguna en todo lo demás, se precavería el temido inconveniente de la falta de equilibrio nacional, pues en caso que este se quebrase una u otra vez, en virtud de la alternativa del generalato, era consiguiente restablecerse sin mucha dilación.

2. a Que es así mismo conveniente el igual número de hábitos respectivo a la mayor o menor magnitud de las naciones.

3. ${ }^{\text {a }}$ Que la repartición nacional de las abadías es disconveniente por ocasionada a que en muchas ocasiones se coloquen sujetos poco aptos en ellas.

4. ${ }^{a}$ Que aún es mucho más disconveniente y peligrosa la igualdad nacional en cátedras, púlpitos y administraciones económicas; tanto que, continuándose por

\footnotetext{
${ }^{80}$ Epiqueya: "Interpretación benigna y prudente de la ley según las circunstancias del tiempo, lugar y persona" (Diccionario de español jurídico, RAE).
} 
algún tiempo considerable, se puede temer en la religión una casi total ruina de la literatura y una notable diminución de la hacienda de que con secuela casi (o sin casi) forzosa resultará un gravísimo detrimento en la observancia.

24. Mas, ¿quid faciendum ${ }^{81}$, ¿qué remedio? Supongo que en punto de abadías ya no se puede tocar sin nuevo recurso a la silla apostólica, en que no sé si se encontrarán algunos tropiezos de difícil desembarazo, mas para la distribución de los oficios inferiores, atendiendo principalmente al mérito y aptitud de los sujetos, juzgo que no es menester interponer nueva súplica a su Santidad, porque la Bula expedida para la repartición de oficios por naciones deja (a mi parecer) arbitrio bastante para la excepción que propongo respecto de los empleos literarios y económicos.

25. Fúndome en aquellas palabras de la Bula en que, después de ordenar que los hábitos se repartan con igualdad entre los cuatro partidos o nacionalidades, esto es, una quarta parte de los hábitos de cada uno de ellos, prosigue así: «et quod eadem proportione distribuerentur officia praecipue abbatia ita quod cum sint quadraginta una abbatia», etc ${ }^{82}$. ¿Quién no ve que aquella parte de la cláusula, «praecipue abbatia» está por demás con notoria superfluidad si la mente del Papa fuese que en la distribución de los demás oficios se observase la atención al número de los nacionales con la misma exactitud que en la distribución de las abadías? Luego es evidente que el intento de su Santidad fue dejar al arbitrio de los eligentes la inobservancia de aquella regla en algunas circunstancias. Y como entre estas la de mayor peso es la desigualdad en la aptitud y mérito de los individuos de diferentes naciones comparados unos con otros, se sigue que, aun estando a la letra de la Bula, se puede en muchas ocasiones preferir la consideración del mérito personal a la de la nación para la distribución de los oficios.

26. Esto es lo que en orden al asunto propuesto me ha parecido representar a Vuestra Reverendísima, quien, por el mayor conocimiento práctico que quiene del presente estado de nuestra Congregación, podrá con más seguro dictamen reformar, adicionar o cercenar en todo lo que llevo dicho.

Nuestro Señor que a Vuestra Reverendísima muchos años, etc.

Agosto, 27, de 1755.

Nuestro Reverendísimo Padre General de San Benito.

Besa la mano de vuestra reverendísima su más humilde, rendido hijo y servidor.

Fray Benito Feijoo.

\footnotetext{
${ }^{81}$ Literalmente, ‘qué se ha de hacer?’.

${ }^{82}$ El texto latino, procedente de la bula citada en la n. 77, podría traducirse como: 'Y que en la misma proporción se distribuyeran cargos, sobre todo en una abadía, de tal manera que, aunque hubiera cuarenta, [sería como si hubiese] una sola abadía'.
} 


\section{APARATO CRÍTICO POSITIVO}

Por aparato crítico positivo ${ }^{83}$ ha de entenderse aquel en el que se precisan tanto los testimonios que presentan la lectura adoptada como los que divergen de ella. De tal modo, después de cada lección indicamos en qué manuscritos se halla presente, tras de lo que se inserta un corchete de cierre; la lección no adoptada, siempre fuera del corchete, va también seguida por la abreviatura del testimonio que la ofrece. Para indicar el lugar en que se ubica cada variante, damos en negrita el número de párrafo. Sea como fuere, como ya se ha dicho, el número y profundidad de las variantes es bastante escaso, pues los manuscritos son cercanos entre sí y cercanos al original.

Titulo Carta de nuestro reverendísimo padre mastro Feijoo al reverendísimo Lasanta, General de la Congregación de San Benito de Valladolid, sobre la providencia de la cuatripartita B] Carta en que el ilustrísimo y reverendísimo Feijoo, benedictino, da su parecer en punto de cuatripartita A; Sin título C 1. conveniencias e inconvenientes $\mathrm{A}, \mathrm{C}$ ] conveniencias o inconvenientes $\mathrm{B}$ 3. notable mutación $\mathrm{B}$ ] notable immutación $\mathrm{A}, \mathrm{C} \|$ ni la más leve apariencia de tal motivo $\mathrm{B}, \mathrm{C}$ ] ni más leve apariencia de tal modo A 4. para su sucesor $\mathrm{A}, \mathrm{C}$ ] para sucesor $\mathrm{B} \|$ prendas $\mathrm{B}, \mathrm{C}]$ prensa $\mathrm{A} \|$ tan condecorado A, B] tan decorado C $\|$ Capítulo del año de 37 para B] Capítulo del año de 45 para $A$, C 5. y no sé si también de otros oficios A, C] y no sé si de otros oficios B 6. Nuestra Señora del Bueso A, B] Nuestra Señora del Hueso C 7. Nuestra Señora del Bueso A, B] Nuestra Señora del Hueso $\mathrm{C} \|$ verisímilmente habrá habido $\mathrm{B}, \mathrm{C}]$ verisímilmente había habido $\mathrm{A} \|$ igualmente y aun más superfluo $\mathrm{B}, \mathrm{C}$ ] igualmente aun más superfluo A 8. otras. Y es verosímil $\mathrm{B}, \mathrm{C}]$ otras. Es verosímil A $\|$ comunísimo repararse $\mathrm{A}, \mathrm{B}]$ comunísimo reparse $\mathrm{C}$ 9. cátedra y púlpito $\mathrm{A}, \mathrm{B}]$ cátedra y púlpitos $\mathrm{C} \mathbf{1 2}$. Cristo B, C] Jesucristo A $\|$ quejosa B, C] quejoso A 13. en ellas A, C] en ella B 14. se hacen más visibles $A, C]$ se han más visibles $B$ 15. igualar en ella $A, C]$ igualar ellos $\mathrm{B} \|$ abunde mucho más de $\mathrm{A}, \mathrm{C}]$ abunde de mucho más de $\mathrm{B} \|$ entrando a la parte $\mathrm{A}, \mathrm{B}$ ] entrando a la partición $\mathrm{C}$ 17. por evitar $\mathrm{A}, \mathrm{C}$ ] para evitar $\mathrm{B}$ $\|$ peligrosos, lo cual lo es $\mathrm{A}, \mathrm{B}$ ] peligrosos, cual lo es $\mathrm{C} \mathbf{1 8}$. algunos sujetos muy proporcionados $\mathrm{B}, \mathrm{C}]$ algunos muy proporcionados $\mathrm{A} \mathbf{2 0}$. Acuérdome de que $\mathrm{A}$, $\mathrm{C}$ ] Acuérdome que $\mathrm{B} \|$ en conversación de un sujeto $\mathrm{B}, \mathrm{C}$ ] en conversación a un sujeto A 21. acierto en todas las cosas B, C] acierto en las cosas A 23. disconveniente $\mathrm{A}, \mathrm{B}$ ] desconveniente $\mathrm{C} \mathbf{2 5}$. muchas ocasiones preferir la consideración $\mathrm{B}$, $\mathrm{C}$ ] muchas ocasiones la consideración A Fecha y firma su más humilde, rendido hijo B] su más rendido hijo A; omitida en C.

\footnotetext{
${ }^{83}$ Alberto Blecun, Manual de crítica textual, Madrid, Castalia, 1983, pág. 147.
} 


\section{BIBLIOGRAFÍA}

Aguilar Piñal, Francisco, "La primera carta cruzada entre Campomanes y Feijoo", Boletín del Centro de Estudios del Siglo XVIII, 1 (1973), págs. 14-20.

Álvarez Barrientos, Joaquín, "Para la historia de una amistad: Feijoo (1676-1764) y Sarmiento (1695-1772)", en Inmaculada Urzainqui y Rodrigo Olay Valdés (eds.), Con la razón y la experiencia. Feijoo 250 años después, Oviedo, Instituto Feijoo de Estudios del Siglo XVIII-Universidad de Oviedo; Ayuntamiento de Oviedo; Trea, 2016, págs. 489-508.

Álvarez de Miranda, Pedro, Palabras e ideas. El léxico de la Ilustración temprana en España, Madrid, Real Academia Española, 1992.

Álvarez de Miranda, Pedro, "Los paratextos de las obras de Feijoo", en Inmaculada Urzainqui y Rodrigo Olay Valdés (eds.), Con la razón y la experiencia. Feijoo 250 años después, Oviedo, Instituto Feijoo de Estudios del Siglo XVIII-Universidad de Oviedo; Ayuntamiento de Oviedo; Trea, 2016, págs. 334-335.

Álvarez de Toledo, Luisa, "En torno a una carta inédita de Feijoo", Revista de Literatura, 98 (1987), págs. 564-573.

Arias Cuenllás, Maximino, Historia del monasterio de San Julián de Samos, Samos, Monasterio de Samos, 1992.

Arias, Maximino, "Catorce cartas de Feijoo a Sarmiento", Boletín del Centro de Estudios del Siglo XVIII, 4-5 (1977), págs. 5-69.

Barreiro Mallón, Baudilio, "Los problemas del clero vistos desde las Juntas del Reino de Galicia, 1599-1750", Obradoiro de Historia Moderna, 14 (2005), págs. 7-38.

Barrerio Mallón, Baudilio, El tabaco y el incienso. Un episodio compostelano del siglo XVII, Vigo, Nigratrea-Consorcio de Santiago, 2009 (Libros da Brétema, 15).

Benedictus Papa XIV ad futuram rei memoriam. Nuper pro parte Dilectorum Filiorum Abbatis Generalis, \& Monachorum Congregationis Vallisoletanae Ordinis Sancti Benedicti Congegationi Venerabilium Fratrum nostrorum Sanctae Romanae Ecclesiae Cardinalium negotiis, \& consultationibus Episcoporum, \& Regularium praepositae exposito, quod anno 1745, Romae, Typographia Reverendae Camerae Apostolicae, 1749.

Blecua, Alberto, Manual de crítica textual, Madrid, Castalia, 1983.

Caso González, José Miguel, "Los benedictinos asturianos y la Ilustración”, en Semana de Historia del monacato cántabro-astur-leonés, Oviedo, Monasterio de San Pelayo de Oviedo, 1982, págs. 635-640.

Caso González, José Miguel y Cerra Suárez, Silverio, Benito Jerónimo Feijoo. Obras completas. T. I: Bibliografia, Oviedo, Instituto Feijoo de Estudios del Siglo XVIII, Universidad de Oviedo, 1981.

Constituciones de la Congregación de Nuestro Glorioso Padre San Benito de España e Inglaterra, Madrid, Imprenta Real, 1671.

Constituciones de la Congregación de nuestro glorioso padre San Benito de España e Inglaterra, Madrid, Viuda de Melchor Álvarez, 1706.

Delpy, Gaspard, Bibliographie des sources françaises de B. Feijoo, París, Hachette, 1936. 
Difiniciones cistercienses de la Sagrada Congregación de San Bernardo y Observancia de Castilla, Valladolid, Viuda de Santander, 1786.

Domínguez Ortiz, Antonio, La sociedad española en el siglo XVII, t. II, El estamento eclesiástico, Madrid, Consejo Superior de Investigaciones Científicas, 1970.

Dubuis, Michel, "Virtud y letras. Fray Martín Sarmiento aboga por la implicación a la lectura y al estudio en la congregación de Valladolid", en Silos. Un milenio. Actas del Congreso Internacional sobre la Abadía de Santo Domingo de Silos, t. III, Burgos, Universidad de Burgos, 2003, págs. 589-600.

Dubuis, Michel, "San Vicente de Salamanca, inicial de "movimiento erudito" en el tránsito del siglo XVII al siglo XVIII", en Pierre Civil y Françoise Crémoux (eds.), Nuevos caminos del hispanismo. Actas del XVI Congreso de la Asociación Internacional de Hispanistas, Madrid-Frankfurt an Main, Iberoamericana-Vervuert, 2010, págs. 74-84.

Dubuis, Michel, "Del concepto de un movimiento erudito, componente de la Pre-Ilustración", Cuadernos de Estudios del Siglo XVIII, 30 (2020), págs. 165-190.

Feijoo, Benito Jerónimo, Teatro crítico universal, t. III, Madrid, Francisco del Hierro, 1729.

Feijoo, Benito Jerónimo, Suplemento del Teatro crítico, Madrid, Herederos de Francisco de el Hierro, 1740.

Feijoo, Benito Jerónimo, Obras completas. T. III: Cartas eruditas y curiosas, II, ed. de Inmaculada Urzainqui, Eduardo San José Vázquez y Rodrigo Olay Valdés, Oviedo, Instituto Feijoo de Estudios del Siglo XVIII; Ayuntamiento de Oviedo; KRK, 2018.

Feijoo, Benito Jerónimo, Obras completas. T. VII. Poesía, ed. de Rodrigo Olay Valdés, Oviedo, Instituto Feijoo de Estudios del Siglo XVIII, Universidad de Oviedo, Ayuntamiento de Oviedo, 2019.

Fernández Flórez, José Antonio, "La Congregación benedictina de Valladolid en el siglo XVIII", en Francisco Gimeno Blay (ed.), Erudición y discurso histórico: las instituciones europeas (s. XVIII-XIX), Valencia, Universitat de Valencia, 1993, págs. 101-128.

Fernández Ortiz, Guillermo, "La crisis de los bernardos castellanos según un impreso de la Biblioteca Universitaria de Zaragoza. Estudio y edición", Cuadernos de Estudios Borjanos, 59 (2016), págs. 135-153.

Frenz, Thomas, I documenti pontifici nel medioevo e nell'etá moderna, El Vaticano, Scuola Vaticana di Paleografia, 1989.

García Díaz, Noelia, El epistolario de Benito Jerónimo Feijoo (en los inicios del ensayo moderno), Tesis doctoral, Oviedo, Universidad de Oviedo, 2016.

García Díaz, Noelia, "Corresponsales americanos de Benito Jerónimo Feijoo en las redes de Martín Sarmiento", en Gloria Ángeles Franco Rubio, Natalia González Heras y Elena de Lorenzo Álvarez (coords.), España y el continente americano en el siglo XVIII, Gijón, Trea, 2017, págs. 413-430.

González Caizán, Cristina, "Correspondencia erudita entre don Agustín Pablo de Ordeñana y el Padre Feijoo”, BROCAR, 23 (1999), págs. 59-86.

González Santos, Javier, "Contribución del Padre Feijoo a la fábrica de la nueva iglesia del monasterio de San Julián de Samos (Lugo). Un capítulo documentado de la historia de la arquitectura y de la edición de libros en España”, Cuadernos de Estudios Gallegos, 130 (2017), págs. 313-356. 
Guía de forasteros en Madrid para el año de 1842, Madrid, Imprenta Nacional, [s. a.].

López García, José Miguel, La transición del Feudalismo al Capitalismo en un señorío monástico castellano. El abadengo de la Santa Espina (1147-1835), Valladolid, Junta de Castilla y León, 1990.

Mabillon, Jean, Tratado de los estudios monásticos, Madrid, Viuda de Mateo Blanco, 1715, 2 vols.

Martínez de la Escalera, José, "Isla ante Feijoo", en Homenaje a Pedro Sainz Rodríguez, t. III, Madrid, Fundación Universitaria Española, 1986, págs. 471-486.

Mestre, Antonio, "Correspondencia Feijoo-Mayans en El Colegio del Patriarca", Anales del Seminario de Valencia, 4 (1964), págs. 149-186.

Noval, Guadalupe de la, "Cuatro cartas autógrafas del Padre Feijoo al Padre Sarmiento", Yermo, Cuadernos de Historia y de Espiritualidad Monástica, 2 (1964), págs. 262-265.

Pérez de Castro, José Luis, "Dos cartas inéditas del padre Feijoo a don Pedro Peón (julio de 1739)", en Inmaculada Urzainqui y Rodrigo Olay Valdés (eds.), Con la razón y la experiencia. Feijoo 250 años después, Oviedo, Instituto Feijoo de Estudios del Siglo XVIIIUniversidad de Oviedo; Ayuntamiento de Oviedo; Trea, 2016, págs. 519- 532.

Rabikauskas, Paulius, Diplomática pontificia, Roma, Editrice Pontificia Università Gregoriana, 1980.

Rey Castelao, Ofelia, "El clero regular de la diócesis compostelana en la Edad Moderna", en José García Oro (coord.), Historia de las diócesis españolas. T. XIV: Iglesias de Santiago de Compostela y Tuy-Vigo, Madrid, Biblioteca de Autores Cristianos, 2002, págs. 352408.

Rey Castelao, Ofelia, "El clero regular", en José García Oro (coord.), Historia de las diócesis españolas. T. XV: Iglesias de Lugo, Mondoñedo-Ferrol y Orense, Madrid, Biblioteca de Autores Cristianos, 2002, págs. 137-148.

San José Vázquez, Eduardo, “Corresponsales peruanos de Feijoo”, en Inmaculada Urzainqui y Rodrigo Olay Valdés (eds.), Con la razón y la experiencia. Feijoo 250 años después, Oviedo, Instituto Feijoo de Estudios del Siglo XVIII-Universidad de Oviedo; Ayuntamiento de Oviedo; Trea, 2016, págs. 533-548.

Saurin de la Iglesia, María Rosa, "Un corresponsal del P. Feijoo: Joaquín Saurin Robles", Cuadernos de Estudios del Siglo XVIII, 28 (2018), págs. 311-342.

Simón Díaz, José, "Una carta inédita del P. Feijoo”, Cuadernos de Estudios Gallegos, 9 (1948), págs. 150-151.

Urzainqui, Inmaculada, "Estudio introductorio", en Benito Jerónimo Feijoo, Obras completas, t. II, Cartas eruditas y curiosas, I, ed. de Inmaculada Urzainqui y Eduardo San José Vázquez, Oviedo, Instituto Feijoo de Estudios del Siglo XVIII; Ayuntamiento de Oviedo; KRK, 2014, págs. 15-134.

Urzainqui, Inmaculada, "Feijoo y su autorrepresentación como escritor", en Elena de Lorenzo Álvarez (coord.), Ser autor en la España del siglo XVIII, Gijón, Trea, 2017, págs. 51-82.

Urzainqui, Inmaculada, "La república amistosa de las Cartas eruditas de Feijoo", Dieciocho. Hispanic Enlightenment, Anejo 5 (2019), págs. 373-398. 
Vivancos, Miguel C., Catálogo del Archivo del Monasterio de Santo Domingo de Silos, Silos, Abadía de Silos, 2006.

Vivancos, Miguel C., "Mariño, Anselmo", Diccionario Biográfico de la Real Academia de la Historia [en línea], disponible en <http://dbe.rah.es/biografias/56174/anselmo-marino > [Consulta: 23/05/2020].

Zaragoza Pascual, Ernesto, Los Generales de la Congregación de San Benito de Valladolid (1613-1701), t. IV, Silos, Abadía de Silos, 1982.

Zaragoza Pascual, Ernesto, Los Generales de la Congregación de San Benito de Valladolid (1701-1801), t. V, Silos, Abadía de Silos, 1984.

Zaragoza Pascual, Ernesto, "Reivindicación del generalato de la Congregación de Valladolid para los monjes asturianos (1760)", Boletín del Instituto de Estudios Asturianos, 132 (1989), págs. 757-774.

Zaragoza Pascual, Ernesto, "Libros de gradas de los monjes de San Martín Pinario de Santiago de Compostela (1502-1833)”, Estudios Mindonienses, 7 (1991), págs. 471-557.

Zaragoza Pascual, Ernesto, “Abadologio del monasterio de San Vicente de Oviedo", Studium ovetense, 26 (1998), págs. 135-175.

Zaragoza Pascual, Ernesto, "Abadologio del monasterio de Nuestra Señora de la Anunciación del Bueso (1460-1789)", Investigaciones Históricas. Época Moderna y Contemporánea, 21 (2001), págs. 19-45.

Zaragoza Pascual, Ernesto, "Fray Miguel de Herce, un calagurritano ilustre y desconocido", Kalakorikos, 9 (2004), págs. 257-272. 